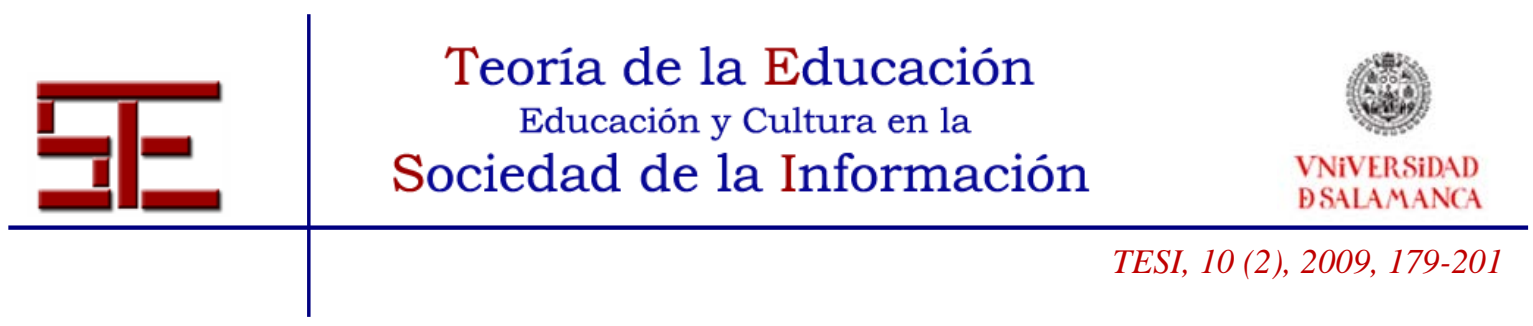

\title{
¿SON LAS TECNOLOGÍAS DE LA INFORMACIÓN CAPACES DE CAMBIAR LAS FORMAS DE HACER POLÍTICA? ESTUDIO DE CASOS EN GALICIA
}

Resumen: En la sociedad industrial los políticos tenían que dominar el lenguaje de la TV pues interesaba más la intensidad de la reacción que la duración del mensaje; debían emplear frases contundentes. En la Sociedad de la Información, con las tecnologías de la comunicación (Tic), esto cambia considerablemente pues la sociedad gana pluralismo y hay más voces que se hacen oír. Aparecen los Blogs como una forma de emitir opinión e información, que podemos considerar como una forma de expresión alternativa (aportan visiones diferentes de las noticias, ignoradas por los grandes medios). Los activistas, partidos políticos, instituciones y ciudadanos encuentran en las Webs, Blogs o Wikis un instrumento para insistir y crear opinión. Las Tic y las herramientas colaborativas de la Web 2.0 generan un mayor interés social en la política, un mayor compromiso e implicación de los individuos y la desaparición de los intermediarios políticos. En estas páginas se muestra una reflexión sobre los impactos de las Tic en la política a nivel teórico, y los resultados de un análisis cualitativo de casos a partir de la observación del uso que hacen de las Tic la plataforma ciudadana “Nunca Máis”, el gobierno autónomo de la Xunta de Galicia, el Parlamento de Galicia y el partido político Bloque Nacionalista Galego.

Palabras clave. E-Gobierno, E-Democracia, participación ciudadana, sociedad de la información, activismo político.

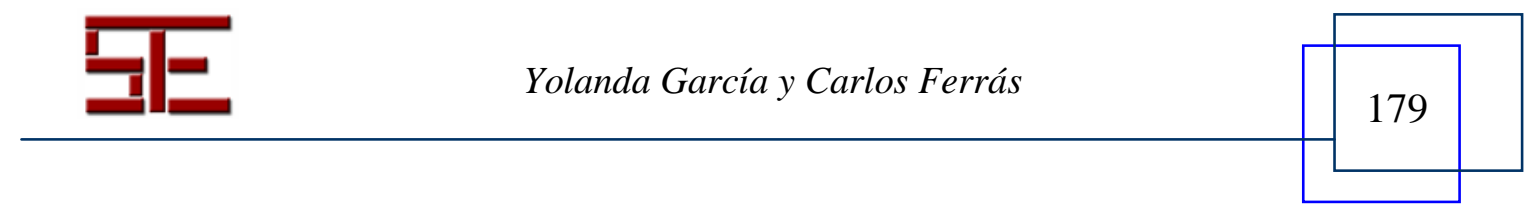




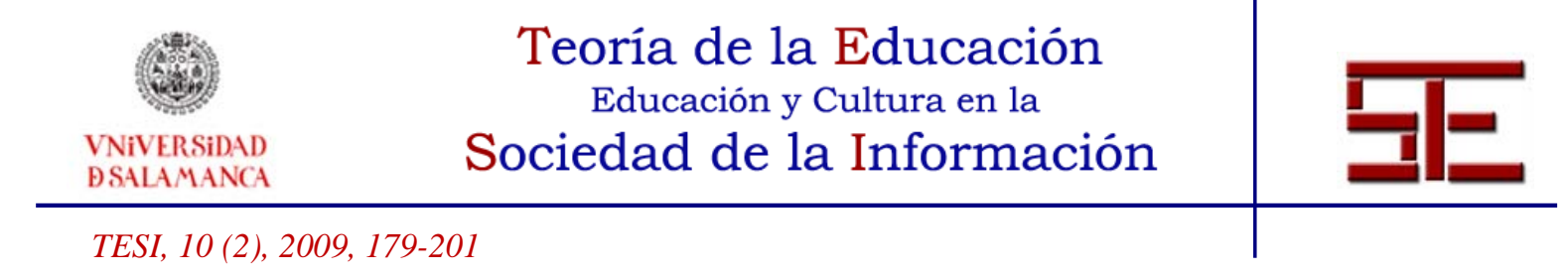

\title{
ARE THE INFORMATION TECHNOLOGIES CHANGING POLITICS? CASE STUDY IN GALICIA
}

\begin{abstract}
In the industrial society, politicians had to command the language TV since the intensity of the reaction was more important than the length of the message. They had to make categorical statements. In the Information Society with information and communication technologies (TICs), this changes to a great extent due to pluralism and the fact that more people make themselves heard. Blogs appear as a way to give opinion and information, and can be considered as an alternative form of expression -blogs give different views on news ignored by the main media-. Activists, political parties, organizations and citizens use websites, blogs or wikis as a means to insist and create opinion. TICs and cooperative tools of Web 2.0 increase people's interest in politics, individual commitment and participation and cause political mediators to disappear. This paper presents a reflection on the impact of TICs on the theory of politics, and the results of a quantitative analysis of cases from the observation of how TICs are used on the social platform "Nunca Máis”, as well as by the autonomous government Xunta de Galicia, the Parliament of Galicia and the political party Bloque Nacionalista Galego.
\end{abstract}

Key words. E-Government, E-Democracy, Civic Participation, Information Society, Political Activism.

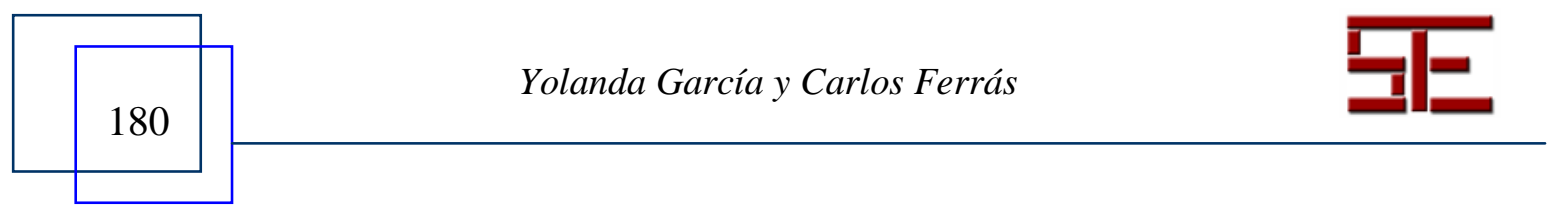




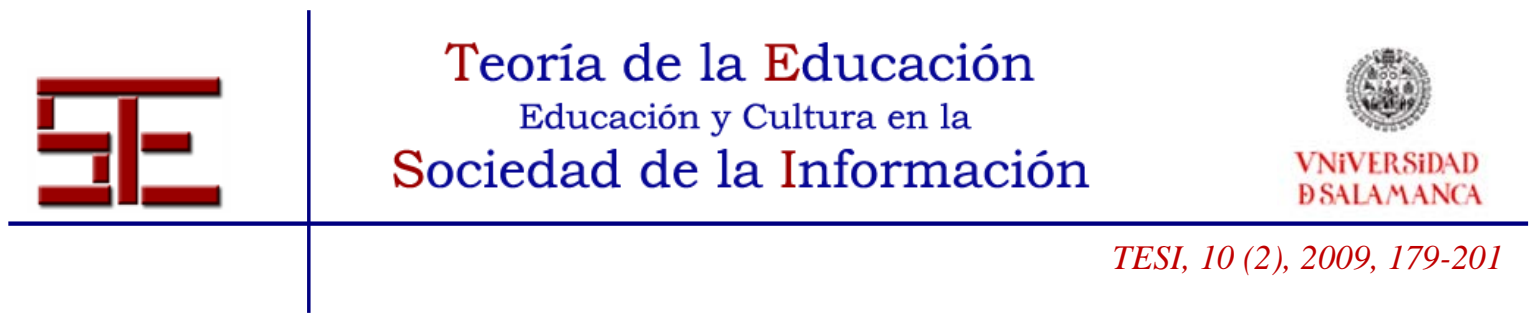

\title{
¿SON LAS TECNOLOGÍAS DE LA INFORMACIÓN CAPACES DE CAMBIAR LAS FORMAS DE HACER POLÍTICA? ESTUDIO DE CASOS EN GALICIA
}

\author{
Yolanda García Vázquez \\ yolanda.garcia.vazquez@usc.es \\ Grupo de Investigación Sociedad, Tecnología y Territorio GIST. \\ Carlos Ferrás Sexto \\ carlos.ferras@usc.es \\ Universidad de Santiago de Compostela.
}

\section{1.- INTRODUCCIÓN.}

En las sociedades occidentales la participación política está en decadencia desde décadas (Batlle y Cerrillo 2006). Los canales tradicionales de comunicación unidireccional vinculados a la televisión o a la radio no fueron capaces de superar la crisis de la democracia participativa. Torres (2005) considera que la política democrática es comunicación y que la transparencia, la rendición de cuentas, se sostienen en la comunicación bidireccional; de contacto directo político-ciudadano. Los comportamientos electorales pueden cambiar en función de la comunicación y en los comicios municipales el conocimiento y comunicación tiene tanto peso como la ideología en la decisión del voto; sin embargo, en las elecciones generales los medios de comunicación tienen mayor influencia en el voto del ciudadano. En la sociedad industrial los políticos tenían que dominar el lenguaje de la TV pues interesaba más la intensidad de la reacción que la duración del mensaje; debían emplear frases contundentes. En la Sociedad de la Información, con la Internet, esto cambia considerablemente pues la sociedad gana pluralismo y hay más voces que se hacen oír. Aparecen los Blogs como una forma de emitir opinión e información, que podemos considerar como una forma de periodismo alternativo (aportan visiones diferentes de las noticias, ignoradas por los grandes medios).

En la Sociedad de la Información los Blogs políticos se multiplican enormemente y desborda el debate tradicional unidireccional. Los activistas encuentran en la Web, en el Blog o en el Wiki un instrumento para insistir y crear opinión. Particularmente coincidimos con Torres (2005) en que las herramientas de comunicación electrónica son positivas pues rompen el monopolio informativo y permiten cuestionar la información libremente. Permiten aportar ideas y restituir el pensamiento político.

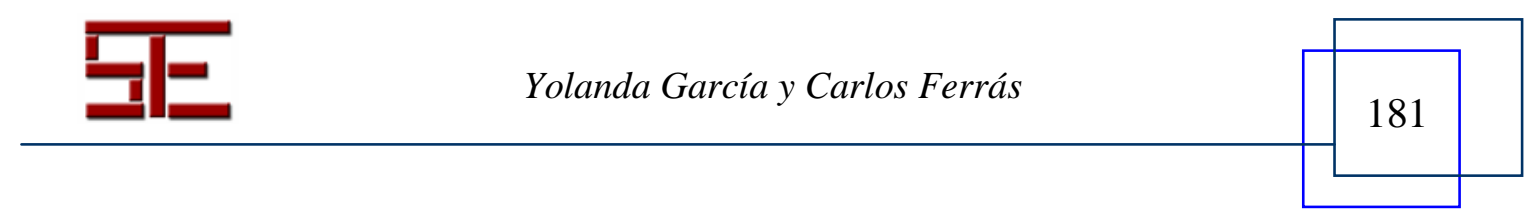




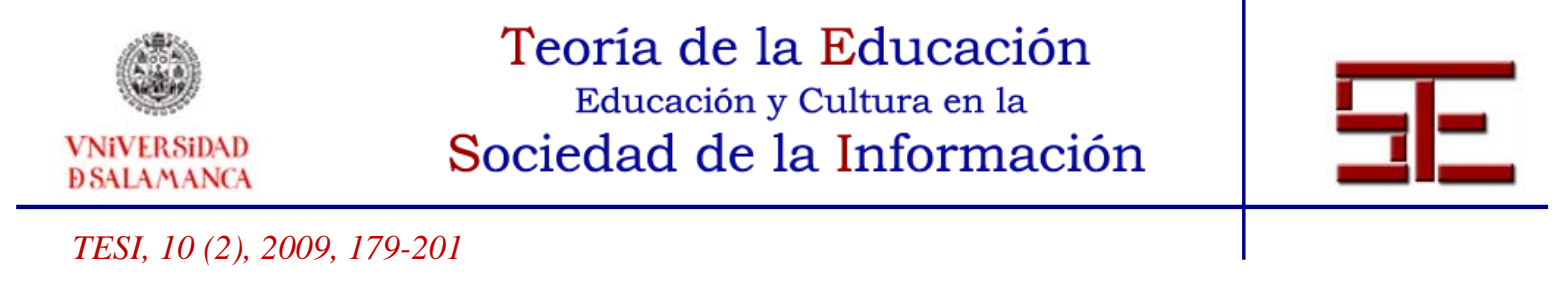

En estas páginas presento una reflexión teórica acerca de las capacidades de las Tic para transformar las formas tradicionales de hacer política. A partir de la utilización de una bibliografía seleccionada de orden internacional, accesible a través de Internet, argumento reflexivamente acerca de las facilidades que ofrecen las nuevas tecnologías para el diálogo entre políticos y ciudadanos; pues permiten establecer canales de comunicación directa, fácilmente accesibles y bidireccionales. Los políticos tienen la oportunidad de conocer la opinión pública sobre sus actividades e iniciativas, debatir socialmente sus propuestas y recabar información social sin la intermediación tradicional de los Mass Media. El estudio de casos en Galicia muestra que no existe una conciencia plena en las organizaciones ciudadanas y políticas acerca de las grandes posibilidades que ofrecen las nuevas tecnologías de la comunicación para la acción social. Durante el mes de noviembre de 2008 procedimos a un análisis cualitativo del uso que hacen de las Tic determinadas organizaciones, como la plataforma ciudadana Nunca Máis, el gobierno autónomo de la Xunta de Galicia, el Parlamento de Galicia y el partido político Bloque Nacionalista Galego. Observamos e intentamos la intercomunicación a través de sus respectivas Web, analizamos los contenidos y servicios, la estructura y concepto de comunicación y la interacción social. Los resultados aunque desiguales muestran que la Web 2.0 no existe y que el contexto socioeconómico es de retraso y marginación en la implantación de la sociedad de la información.

\section{2.- FUNDAMENTOS TEÓRICOS.}

Las Tics pueden incrementar la participación y el mayor flujo de información política en Internet favoreciendo la participación social (Norris, 1999). La literatura positiva sostiene que las Tics y las herramientas colaborativas de la Web 2.0 generan un mayor interés social en la política, un mayor compromiso e implicación de los individuos y la desaparición de los intermediarios políticos. Sin embargo, debemos tener presente que la "brecha digital" y el analfabetismo general en el uso inteligente de las herramientas de comunicación bidireccional de la Web 2.0 encarece la obtención de la información para las personas fuera de la línea (off-line). En el nuevo contexto informacional de la Internet las personas tienen más complicado el proceso de selección, procesamiento y asimilación de la información. Se les requiere tener un carácter proactivo del nuevo medio frente al pasivo de la televisión y la radio.

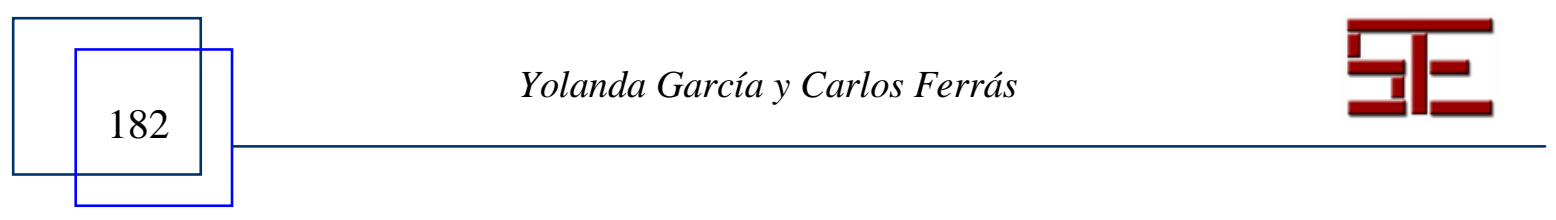




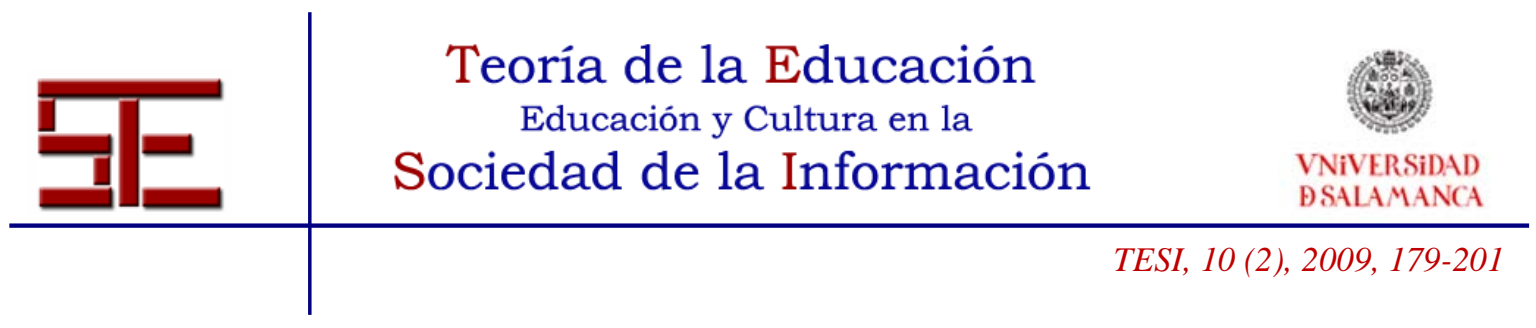

Batlle y Cerrillo (2006) sostienen que el individuo debe obtener beneficios en la acción de informarse. Creen que la participación social aumenta con las Tic siempre que los costes no sean altos para el individuo; y consideran que cuando la información les hace cambiar de opinión los beneficios serán mayores que los costes. Estamos de acuerdo con la afirmación de que el "ignorante racional" no se esfuerza en obtener información si no percibe beneficios; pero podemos preguntarnos por los beneficios que obtienen los Bloggers; ¿Buscan posición política? o ¿Están influidos por una ética Hacker desinteresada? Batlle y Cerrillo (2006) consideran que dependiendo del estrato social los creadores- autores de los Blogs se implican más o menos en los procesos políticos, por lo cual a un hombre de negocios le es rentable estar informado de la política económica. Pero también parece evidente que son muchos los autores de Blogs que ofrecen y obtienen información por ocio o entretenimiento. La literatura positiva argumenta que las Tics pueden permitir el contacto directo sin intermediarios entre gobernantes y gobernados y matiza que esto sería así siempre que los ciudadanos perciban capacidad de influencia, es decir, que sus aportaciones y mensajes sean tenidos en cuenta. Sin embargo, existe un consenso generalizado respecto a la necesidad de impulsar el estudio empírico de casos concretos sobre Tics y política; y esto es así porque no existen datos que demuestren que los conectados tengan mayor participación política respecto a los no conectados. Parece ser que los ciudadanos que utilizan las Tics son los que ya están políticamente movilizados y este hecho corrobora que las comunidades virtuales en temas políticos están muy vinculadas y ancladas en las comunidades físicas. Podemos preguntarnos si los lectores de Blogs políticos son exclusivamente partidarios y seguidores ideológicos del autor. De nuevo se echan de menos estudios empíricos de caso. Sin embargo, para Norris (2004) las personas en línea parecen más predispuestas a la actividad política, no existen distinciones en cuanto al mayor o menor nivel educativo y parece que solo la variable edad es significativa; Norris observa que los jóvenes tienen mayor participación debido al voto electrónico, debates y Chats. Nos podemos preguntar si estos jóvenes realmente inciden en la opinión de los políticos.

En cuanto a la acción colectiva y uso de las Tics, sus efectos favorecen la acción política de los grupos. Las Tics reducen los costes de comunicación, permiten la fácil creación de vínculos políticos entre ciudadanos y reducen los costes relativos a la formación de grupos de opinión y de comunidades físicas y virtuales. Debemos tener presente que en Internet el espacio y el tiempo no dificultan la acción política de los grupos; estos pueden ejercer acción política sin un control jerárquico y facilitan el encuentro de personas con un mismo interés. Las Tics, los Blogs, Wikis y herramientas

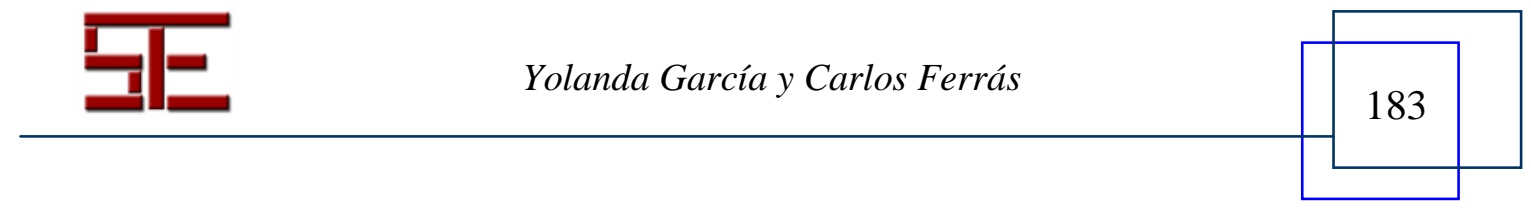




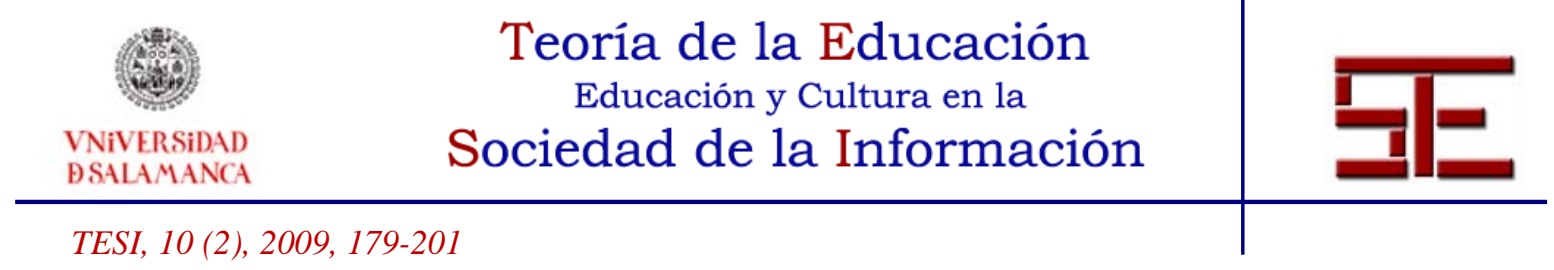

de comunicación on-line, ayudan a construir la organización política y a determinar su naturaleza. Sin embargo, la facilidad para la formación de grupos puede tener efectos perversos (balcanizador), puede derivar en una polarización de los grupos debido a los bajos costes de la formación de dichos grupos y pueden articularse en torno a un único tema. La velocidad, inmediatez, y superación de la barrea espacial de las Tics reducen los costes de la acción colectiva y favorecen la creación de comunidades virtuales pero no establecen vínculos personales fuertes; de ahí que, sea necesaria una retroalimentación virtual-real para poder superar lo efímero y enfatizar la capacidad de influencia política.

Lara Otaola (2007) reflexiona sobre las Nuevas Tecnologías de comunicación y se pregunta si son: ¿Oportunidad o riesgo para la esfera pública y la democracia? Afirma que son nuevas formas de expresión frente a los medios tradicionales. Son más libres, abiertas, democráticas y transforman y amplían nuestras formas de comunicación y participación. Además, Lara Otaola cree que pueden ayudar a conformar una sociedad más democrática, más participativa, y con mayor capacidad de acción frente al poder, con mayor y mejor debate, con más transparencia y rendición de cuentas. Sin embargo, este autor considera que las Nuevas Tecnologías de la comunicación también conllevan la desinformación y subinformación, más propaganda y manipulación, desorientación, antinformación frívola y vacía de contenido.

Norris (2004) muestra teorías y datos empíricos sobre el impacto de las Tics sobre los procesos políticos. Concluye que la asociación entre el acceso a Internet y el activismo político depende de la forma de la participación política considerada, y que el uso de las Tics con finalidades políticas favorecerán los nuevos movimientos sociales, o a las organizaciones de protesta frente a las transnacionales; siendo por ello superiores a los canales políticos tradicionales de las democracias participativas. Lusoli y Ward (2003) creen que el uso colectivo de las Tics favorecen los mecanismos de participación directa, pero también consideran que las organizaciones políticas clásicas siguen ocupando un rol clave en los mecanismos de participación actuales. Constatan que las Tic son utilizadas para la diseminación “Top Down” de información relevante para los miembros de la organización física y no tanto como un instrumento para la discusión interactiva; no constatan ningún efecto Internet en la participación y, consideramos que acertadamente, creen que los individuos inactivos "off-line” siguen inactivos "on-line”.

Para Barrero, Criado y Ramilo (2006) existe relación estrecha entre política y Web 2.0.

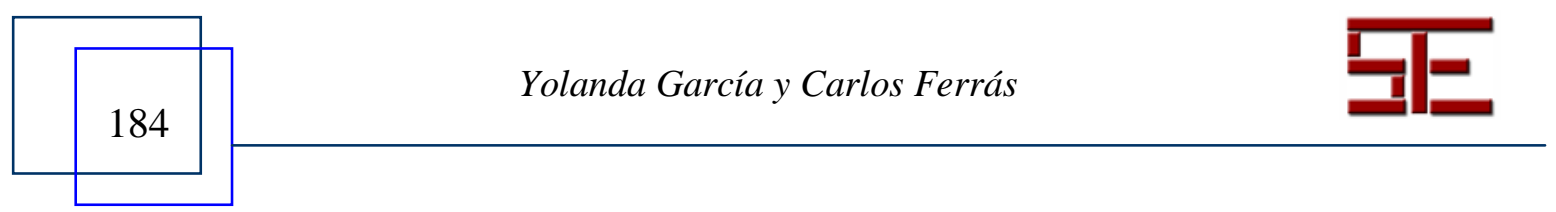




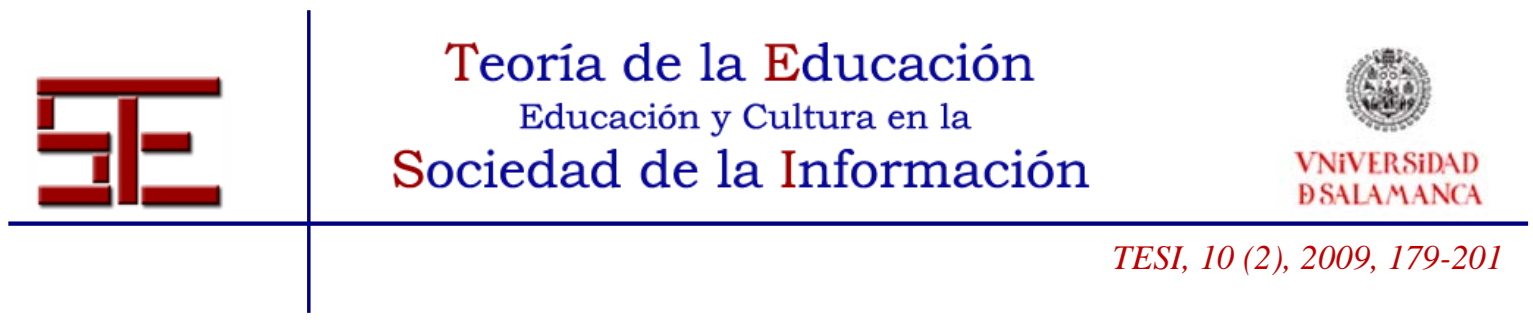

Las Web 2.0 crea redes entre entidades independientemente de que sean Webs, fotografías, personas o cualquier otro tipo de identidad; y consideran que son una vuelta al antropocentrismo que se perdió en la Web 1.0. La política y la Web 2.0, reconoce al ciudadano en el centro de la labor gobernativa; interacción ciudadano-responsables políticos; aunque la incorporación de la filosofía de la Web 2.0 en la esfera política se encuentra en una fase inicial y tiene un contenido fundamentalmente normativo (prestación unidireccional de los servicios a los ciudadanos). Sin embargo los Wikis y Blogs y la Web semántica ya se han convertido en plataforma de participación política para los ciudadanos generando enormes retos respecto de como las administraciones públicas se han relacionado con la ciudadanía. Para Barrero, Criado y Ramilo (2006) las herramientas colaborativas online generan nuevas oportunidades sociales en las democracias representativas; pues el rol de los usuarios-ciudadanos cambia significativamente pasando a ser actores activos en la definición de políticas y normas de gestión. Parece que la Web 2.0 supera la mera y simple la publicación de contenidos políticos en la Red a favor del impulso de la colaboración de ciudadanos individuales o en grupo. Actualmente en Internet los usuarios generan contenidos y utilizan servicios y dejan de ser meros receptores de discursos planos. Colaboración, sencillez, participación, ciudadanía, usuario y trabajo en red son los conceptos clave de la Web 2.0 y tendrán que serlo también de los nuevos procesos políticos que se perfilan en el contexto de la Sociedad de la Información. Coincidimos con Barrero, Criado y Ramilo (2006) cuando afirman que se requiere un cambio cultural fundamental en la política de la Sociedad de la Información; la cual debe superar la figura clásica del político hipercontrolador a favor de la conformación de un político 2.0 catalizador de proyectos. Y esto, parece ser que, solo será posible a través de la educación de los políticos en el uso intensivo de Blogs y otras herramientas de comunicación colaborativa. Los nuevos políticos deberán tener capacidad para adaptarse al nuevo medio, hablar pero también escuchar, adaptarse y aceptar la crítica; en suma deberán ser capaces de hacer política multidireccional.

\section{3.- LA ADMINISTRACIÓN Y EL GOBIERNO ELECTRÓNICO. EL CASO DE LA XUNTA DE GALICIA.}

El Modelo de evaluación de E-Gobierno que hemos decidido utilizar es el denominado "NOIE Model" australiano (Kustelj y Vintar, 2004) que facilita una evaluación compresiva de los servicios diseñados para satisfacer las necesidades de los usuariosciudadanos frente a los propios de la administración pública. El enfoque es muy interesante porque la fragmentación estructural de la administración condiciona la

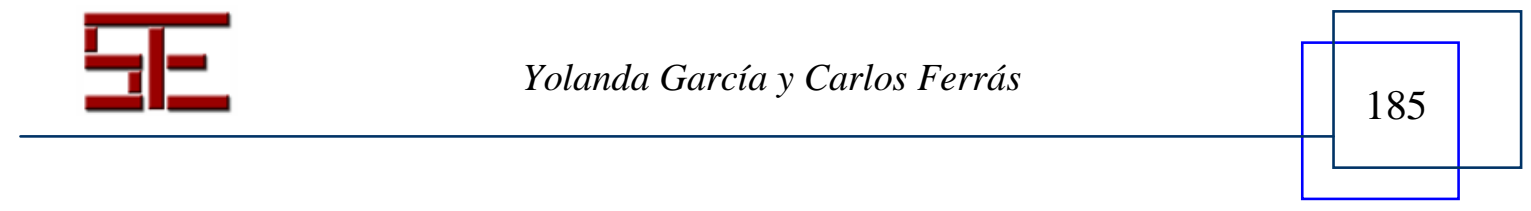




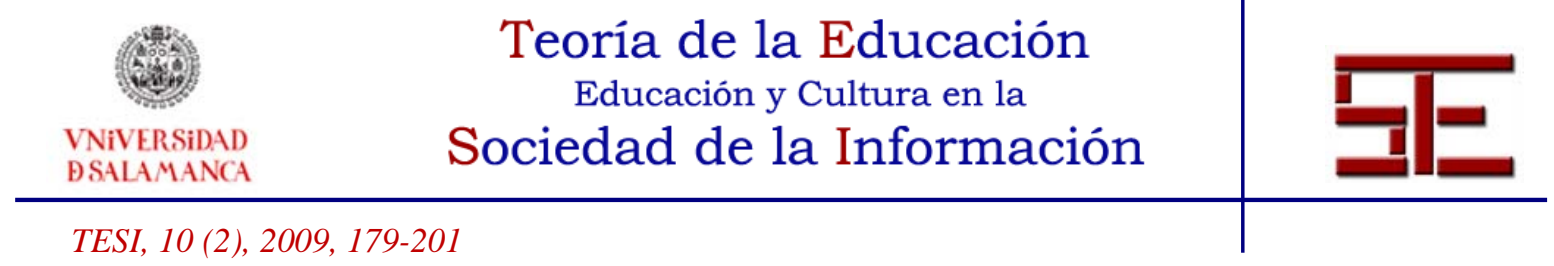

calidad de los servicios que prestan, y diferencia cinco niveles incluyendo la evaluación de los servicios integrados de información y transacción, de disposición de información y de formularios administrativos.

La Xunta de Galicia como entidad de gobierno regional de la Comunidad Autónoma de Galicia tiene entre sus objetivos preferentes la modernización y el desarrollo de la administración electrónica en los ámbitos de su competencia. Para ello la Consellería de Administración Pública promueve acciones concretas siendo la más significativa la dinamización de la Web www.xunta.es/administracion-electronica, la definición y puesta en funcionamiento de un sistema de validación electrónica de documentos y de seguimiento de los procesos y expedientes administrativos. Sin embargo esta Web muestra fragmentación e incluso cierto desorden en la exposición de enlaces e informaciones; no ofrece información clara sobre los objetivos del gobierno regional al respecto y a veces reitera enlaces de forma desestructurada. No existe interacción con el ciudadano ni posibilitan contactos bidireccionales con el administrador de la Web. Este portal está concebido como un nexo de unión de iniciativas inconexas de las diferentes consellerías y órganos de gobierno o gestión de la Xunta de Galicia.

En Galicia el uso de las Tics se encuentra en un estado atrasado; en torno al 65\% de la población total no accede a Internet (datos INE, 2006) y el desarrollo de una cultura informacional es una tarea pendiente. La Comunidad Autónoma cuenta desde el 2007 con el denominado Plan Gallego para la Sociedad de la Información (PEGSI) que enumera varias líneas de acción a desarrollar entre el 2007 y el 2010, entre las que se encuentran la Administración Electrónica. Es un Plan todavía en fase de desarrollo inicial pero muy importante teniendo en cuenta que es la primera vez que se formula y asume como acción de gobierno un Plan específico para el desarrollo de la Sociedad de la Información, que además ha sido impulsado por un gobierno bipartito entre socialistas y nacionalistas.

El gobierno autonómico a través del PEGSI y de la Web institucional deja claro su compromiso con la administración electrónica al considerarla fundamental para facilitar las relaciones de los ciudadanos con la administración y hacer más eficiente la gestión.

Sin embargo, no está nada claro el compromiso en términos económicos pues este dato no trasciende en los documentos hechos públicos al respecto.

En cuanto a la información sobre servicios “on-line”, la administración autonómica posibilita conocer sus características a partir de la Web general del gobierno. En la Web

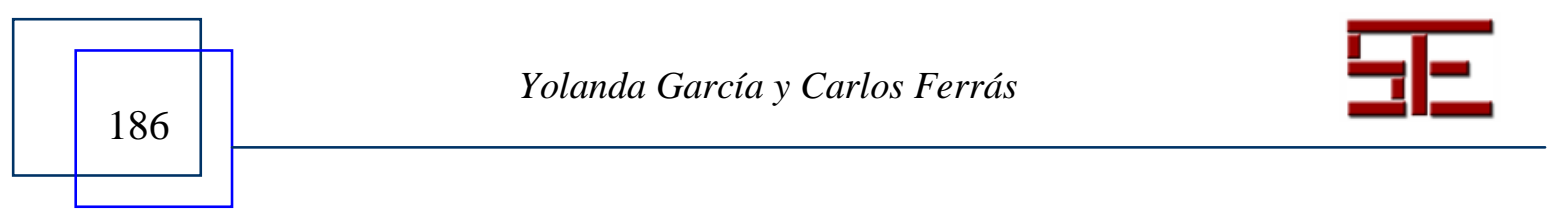




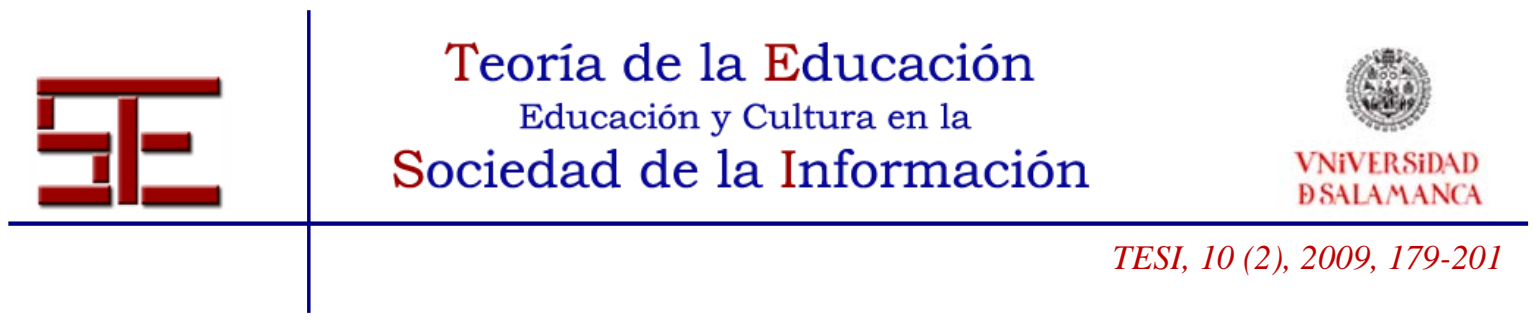

www.xunta.es podemos acceder a enlaces con todos los órganos propios a nivel de consellerías y organismos autónomos.. La observación de las Webs institucionales de las organismos administrativos de la Xunta de Galicia permite comprobar cómo son básicamente concebidas como un canal de información al ciudadano, tanto de contenidos generales como específicos. Básicamente son Webs que permiten interactuar al ciudadano con la administración a través de la descarga de documentos, formularios, estableciendo comunicación bidireccional. De forma restrictiva, existen servicios interactivos de doble vía, es decir, que permiten hacer gestión electrónica de documentos a través de la autentificación de la firma electrónica; sin embargo, las consultas realizadas directamente con los funcionarios nos indican que es un servicio escasamente utilizado. La tramitación de expedientes es posible en casos muy específicos, previa inscripción en registros oficiales, como por ejemplo el de empresas habilitadas para contratar con la Xunta de Galicia, el de investigadores de las universidades dados de alta en un registro especializado, etc. Lo que no parece posible es la tramitación de los pagos electrónicos. Destacan los servicios “on-line” de licitación de obras, acceso al Diario Oficial de Galicia (DOGA), o a servicios especializados como el Banco de Tierras que permite poner en contacto a propietarios de fincas dispuestos a cederlas a cambio de una renta anual.

El modelo de administración electrónica de la Xunta de Galicia obedece a un modelo de control discontinuo; no existe un organismo que dirija y coordine la acción de gobierno al respecto. Por ejemplo, la Consellería de Educación desarrolla su propio portal Web especializado con imagen corporativa propia y al servicio de la comunidad educativa; es decir, orientado hacia la gestión de la red de centros de enseñanza primaria y secundaria, con más de 400.000 alumnos y 40.000 profesores; a nivel de universidades se centra específicamente en la información básica. El "Servizo Galego de Saúde" (SERGAS) desarrolla una plataforma Web al servicio del ciudadano que permite la petición de cita previa en ambulatorios y hospitales, pero todavía está iniciando el proceso de digitalización de los historiales médicos de los pacientes-usuarios. Por su parte la Consellería de Economía ofrece servicios de oficina virtual a los ciudadanos para consultar los expedientes administrativos abiertos.

En cuanto a la formación de los funcionarios en temas de administración electrónica, la Xunta de Galicia dispone de la "Escola Galega de Administración Pública” que oferta numerosos cursos especializados al respecto dirigidos a los funcionarios de cualquier administración pública con sede en Galicia.

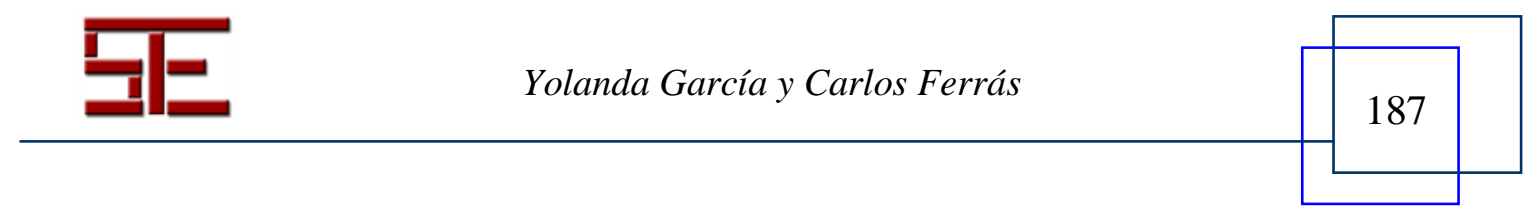




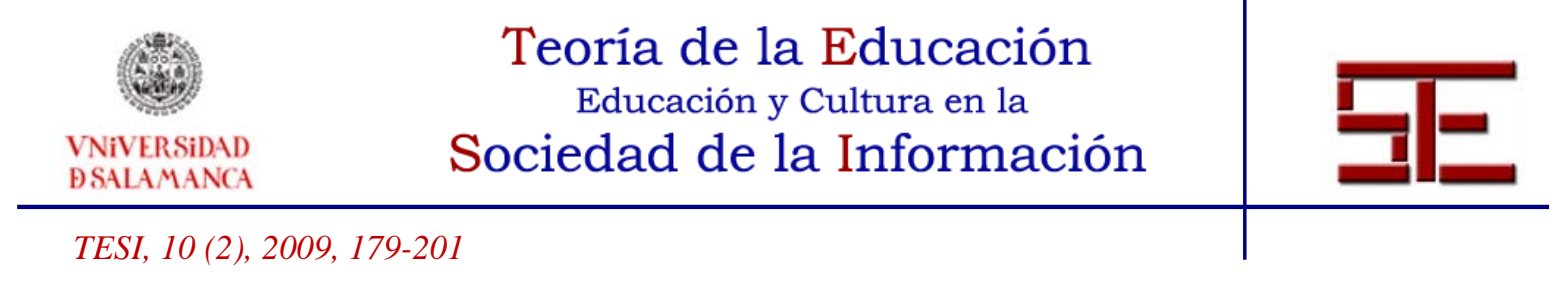

Es interesante la iniciativa de la Consellería de Industria, Dirección General para la Promoción Industrial y la Sociedad de la Información, de impulsar acciones para la formulación de planes municipales de alfabetización digital. Existe una Puerta Única Electrónica a modo de intranet que establece interrelaciones entre las administraciones locales y la administración autonómica; de tal forma que los registros oficiales de los ayuntamientos pueden aceptar y abrir expedientes administrativos dirigidos a instancias autonómicas. Es un servicio integrado de gestión de información que facilita al ciudadano sus relaciones con la administración, evita desplazamientos y promueve el ahorro de energía y tiempo de gestión.

Todo indica que los servicios de administración electrónica de la Xunta de Galicia denotan des-estructuración y desorden. Parece que los órganos de gobierno actuasen descoordinadamente al respecto. Existen iniciativas interesantes pero en un medioambiente social de apatía respecto a la implantación de la Sociedad de la Información; con datos de usuarios de Internet en Galicia inferiores a la media española podemos intuir la poca motivación real de los partidos políticos gobernantes hacia una fórmula efectiva de e-gobierno.

\section{4.- ANÁLISIS DE UN EJEMPLO DE ACCIÓN COLECTIVA: LA PLATAFORMA NUNCA MAIS; WWW.PLATAFORMANUNCAMAIS.ORG}

"Nunca Máis” es una plataforma ciudadana sin entidad jurídica cuyo objetivo declarado es evitar la repetición de desastres ecológicos en Galicia, el castigo de los mismos y la reparación de los daños. Fue creada en Galicia a principios del 2003 pocos días después de que se hundiera el petrolero Prestige frente a las costas gallegas. Esta organización aglutinó desde entonces la respuesta ciudadana al desastre ecológico y a la gestión llevada a cabo por las administraciones implicadas. Con múltiples manifestaciones de variado carácter exigió la declaración de Galicia como zona catastrófica y la inmediata dotación de recursos de todo tipo para reparar las graves consecuencias económicas, sociales, medioambientales y para la salud provocadas por el siniestro; también reclamó la puesta en marcha de mecanismos de prevención que impidieran que hechos como estos se volvieran a repetir en el futuro, y la dimisión de los responsables políticos. Vinculado a "Nunca Máis" se organiza un colectivo de actores y artistas gallegos denominado Burla Negra en mayo de 2005 a consecuencia de la catástrofe de los incendios forestales en Galicia.

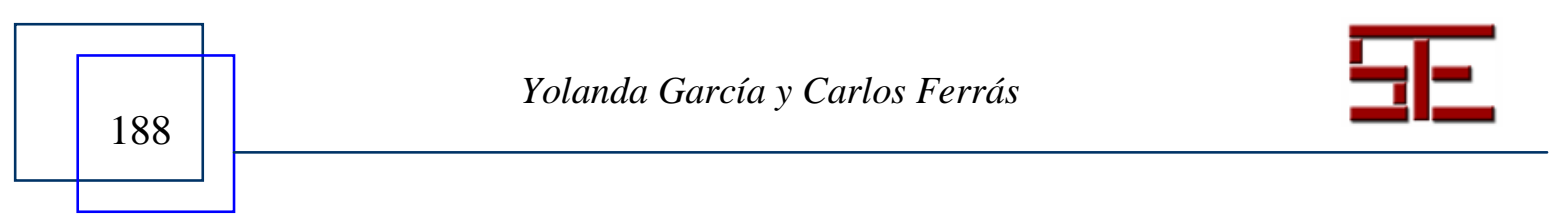




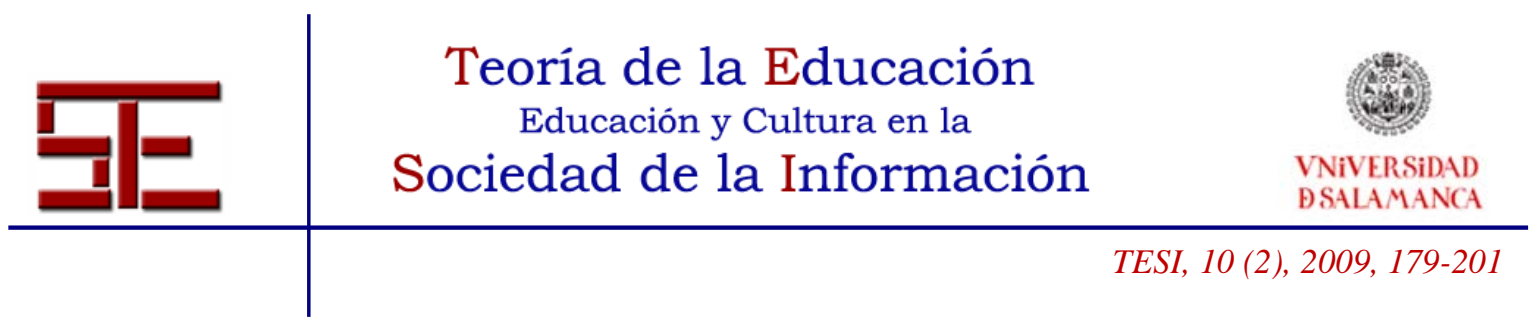

“Nunca Máis” está impulsada inicialmente por 5 organizaciones ecologistas: “Asociación para a Defensa Ecolóxica de Galiza” (ADEGA), “Coordinadora para o Estudio dos Mamíferos Mariños” (CEMMA), "Federación Ecologista Galega” (FEG); "Sociedade Galega de Educación Ambiental” (SGEA) y "Sociedade Galega de Historia Natural”, que deciden a partir de la catástrofe del Prestige el 21 de noviembre de 2002 organizarse para impulsar un movimiento ciudadano de rechazo a las agresiones medioambientales que padece Galicia. Actualmente (noviembre de 2008) en la página Web de "Nunca Máis” aparecen más de 200 asociaciones inscritas como integrantes, apoyados además por colectivos tan diversos como cofradías de marineros, asociación de guardias civiles, asociaciones culturales, vecinales, sindicatos, políticos, etc. Esta plataforma movilizó en el 2002 y años posteriores las manifestaciones más numerosas de la historia de Galicia e incluso, según datos de prensa, llegó a movilizar una manifestación de 1.000.000 de personas en el 2003 en Madrid para pedir responsabilidades políticas por la catástrofe ecológica del petrolero Prestige.

La pagina web www.plataformanuncamais.org es desarrollada técnicamente por el principal periódico digital gallego, que se denomina Vieiros (ver www.vieiros.com).

Además Vieros soporta el servicio de servidor y alojamiento de dicha Web. La Web no muestra contenidos actualizados, incluso no funcionan los enlaces a fotografías, videos y documentos diversos por estar el servidor fuera de uso (noviembre 2008). La información estática del centro de prensa recoge noticias desde la fecha de la catástrofe del Prestige el 21 de noviembre de 2002 hasta el 9 de noviembre de 2005. El foro de debate no funciona, tampoco el sistema de pagos online que enlaza con Caixa Galicia que sin embargo invita a hacer aportaciones económicas.

Resulta interesante la sección de contactos, donde puedes conocer direcciones de correo electrónico de sedes comarcales de "Nunca Máis" distribuidas por toda Galicia; en algún caso incluso con nombre de la persona de contacto y un número de teléfono. Resulta también interesante los enlaces a contactos de "Nunca Máis” fuera de Galicia; pero solo funciona en el caso de Cataluña www.nuncamaiscatalunya.org que paradójicamente tiene noticias más recientes que la Web de la plataforma en Galicia (la última es del 3 de noviembre de 2006); los enlaces con el País Vasco, Granada, Lisboa, no funcionan y en el caso de Europa-Bruselas sorprendentemente enlaza a una Web denominada nuncamais-europa.org de información turística referida a destinos en Europa.

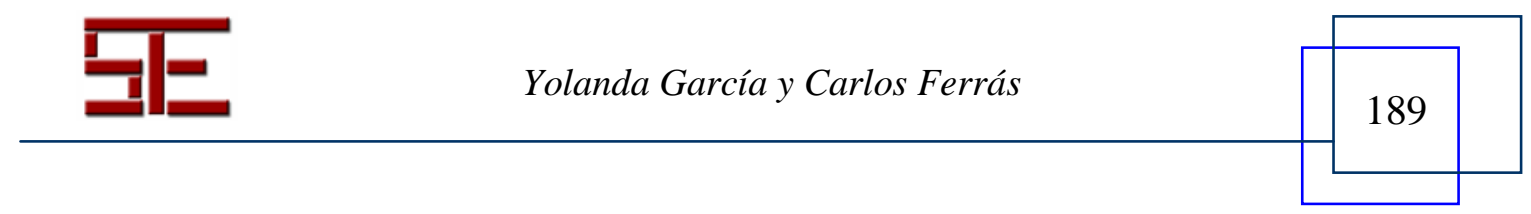




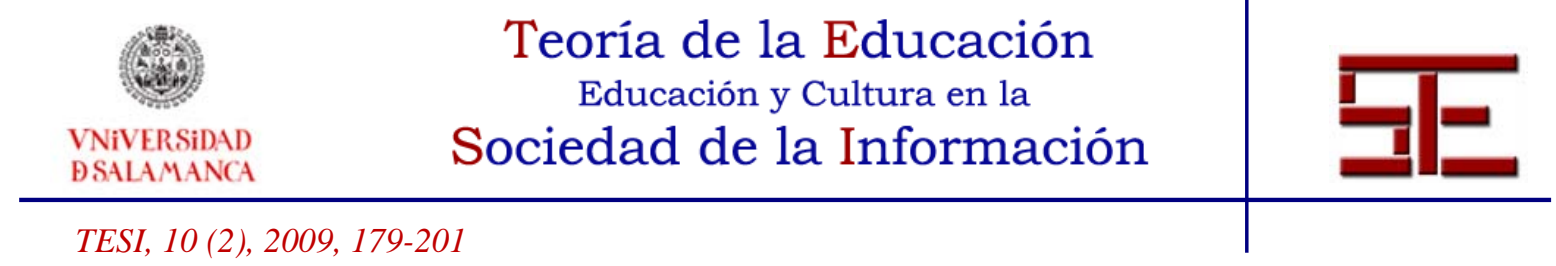

Por otra parte la Web de "Nunca Máis” ofrece la posibilidad de inscribirse en modalidad individual y colectiva a través de un formulario online. Incluso en modalidad individual ofrece la posibilidad de formar parte de colectivos sectoriales de "Nunca Máis” como enseñanza, cultura, salud, etc.

¿Responde al modelo SPIN citado por Bennet (2003)? Teniendo presente que el modelo SPIN se refiere a organizaciones segmentadas, policéntricas, integradas y en red, creemos que efectivamente la Plataforma "Nunca Máis” cumple tales preceptos. La segmentación queda en evidencia en el hecho de que "Nunca Máis" no tiene fronteras rígidas y los diferentes grupos ecologistas y de toda índole que conforman la plataforma ciudadana mantienen su identidad y colaboran, se juntan, para unas acciones y a la vez mantiene su individualidad para otras. Pensemos que en "Nunca Máis” conviven asociaciones tan diversas como por ejemplo cofradías de marineros, la asociación de guardias civiles, entidades culturales, de actores, profesores, médicos, etc. También es policéntrica y desjerarquizada porque tiene múltiples centros de decisión, no existe una "cabeza visible" rectora, la coordinación de diversos nodos en rede es característica; a ello contribuye el hecho de haber nacido como una organización de ciudadanos que reivindican causas justas de gran interés social. Es cierto que no existe un liderazgo individual; sin embargo, al indagar acerca de la estructura se percibe una clara vinculación con las organizaciones políticas de orden Nacionalista. El propio servidor que aloja la Web pertenece a una organización estrechamente vinculada al Bloque Nacionalista Galego (BNG) partido que en el 2008 formaba parte del gobierno autonómico coaligado con el Partido Socialista de Galicia. En cuanto a la integración ideológica se percibe una clara vinculación con movimientos ecologistas, culturales, etc. asociados con valores propios de la izquierda que precisamente buscan y reclaman responsabilidades al gobierno de Partido Popular gobernante en Galicia en el momento de la catástrofe del Prestige en el año 2002.

Respecto del uso que realizan de las TIC, el periodo de mayor dinamismo mediático de "Nunca Máis" estuvo comprendido entre la fecha de la catástrofe ecológica en noviembre de 2002 y finales de 2005. Su página Web parece diseñada como instrumento de comunicación para difusión de datos, fotos, videos, notas de prensa, dossieres documentales de declaraciones de personalidades destacadas; dicha Web impulsa los flujos de información entre el colectivo y los Mas Media (la Web tiene un centro de prensa muy destacado); además, por la estructura de contenidos se intuye como objetivo la creación de contenidos de interés para periodistas. Por otra parte, intenta ser un portal de entrada para nuevos colectivos ciudadanos o individuos que se

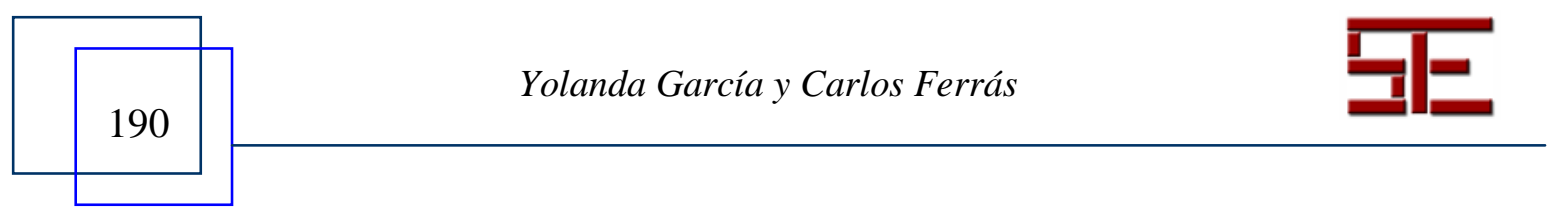




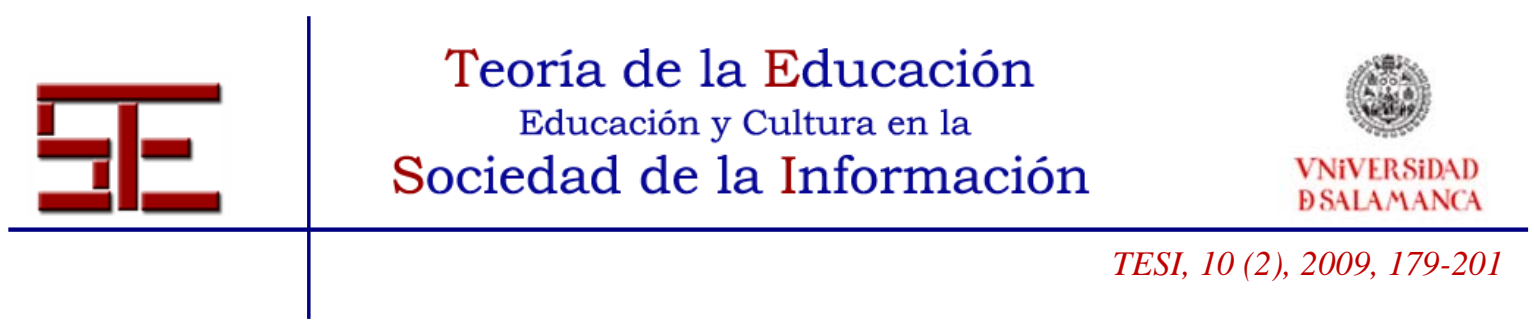

sumen a la causa; facilita los contactos en red a través de correo electrónico con coordinadores distribuidos por diferentes comarcas de Galicia y con importantes ciudades como Barcelona, Bruselas, Lisboa, etc. También usan la Web para captar recursos económicos como donaciones a la "causa" a través de un sistema de pagos online. Sin embargo, todo esto en noviembre de 2008 está paralizado y muchos de sus recursos y aplicaciones no funcionan.

En cuanto a los efectos del uso de las TIC en la consecución de sus finalidades, observamos que han sido un instrumento muy valioso para la concienciación social de la causa ecológica en Galicia. Han permitido acelerar y difundir fácilmente la información sobre las graves consecuencias medioambientales del derrame de petróleo en las costas de Galicia y posicionar a la opinión pública acerca de la depuración de responsabilidades políticas. Los archivos digitales de video, fotografía y noticias y manifiestos de la plataforma ciudadana alimentaron durante meses rotativos de periódicos de ámbito regional, nacional e internacional. Por otra parte, la movilización de más de 200 entidades colectivas difícilmente se podría conseguir si no contaran con las TIC. Pensemos que es una organización policéfala desjerarquizada donde existen múltiples nodos en red.

Desde nuestro punto de vista existe una retroalimentación continua entre acción "online” y "off-line”; la acción "on-line” apoya y facilita la comunicación y sirve de instrumento para la organización de manifestaciones, redacción de manifiestos, o debate-confrontación de ideas. Sin embargo, los actos importantes y significativos de la acción colectiva siempre han sido "off-line”; pensemos en las grandes manifestaciones en las calles de las ciudades gallegas o la gran manifestación celebrada en Madrid en el 2003. Siguiendo las nociones de Norris $(1999,2004)$ observamos que no hay duda de que en el caso de "Nunca Máis" el "mobilization effect” de las TIC ha quedado patente en su trayectoria. Creemos que la diversidad y cantidad de colectivos ciudadanos e individuos vinculados por una causa ecologista y de denuncia a raíz de un acontecimiento de gran impacto como el hundimiento del petrolero Prestige es un argumento al respecto. ¿Sería su capacidad de movilización idéntica sin las TIC? Seguramente la respuesta es negativa. En este sentido las TIC permiten una mayor incidencia social en la toma de decisiones, impulsa una gobernanza, verdaderamente democrática con un poder real de los colectivos ciudadanos organizados. Por otra parte, la "reinforcement theory", también siguiendo a Norris (1999, 2004), no queda totalmente descartada, pues surgen dudas cuando nos preguntamos por la paralización actual de Nunca Máis. Por qué coincide dicha paralización con la llegada al gobierno

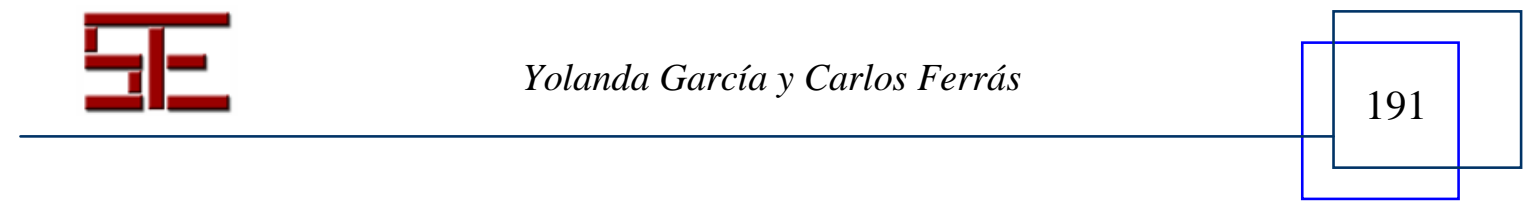




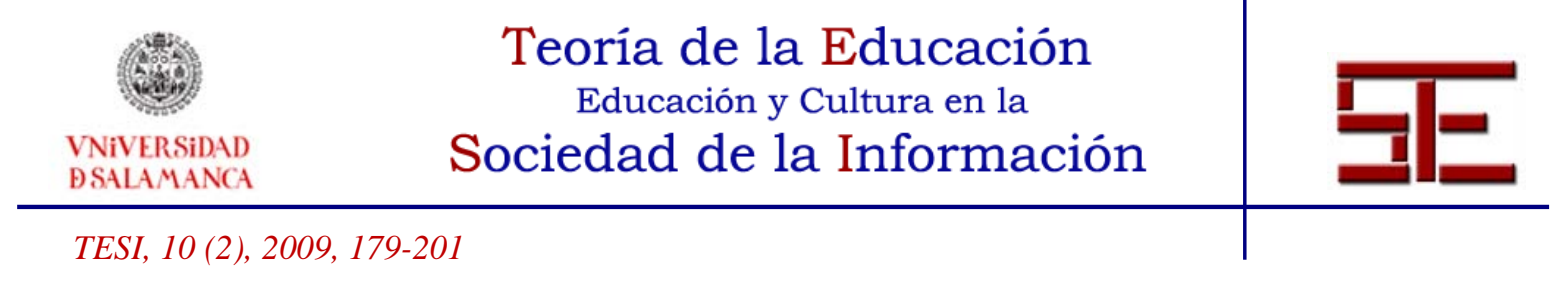

autonómico (Xunta de Galicia) de los partidos del ámbito ideológico de izquierda, BNG y PSOE-PSG; quienes, no lo olvidemos, fueron los auténticos dinamizadores de "Nunca Máis”, con el fin de denunciar, desgastar, al gobierno de Partido Popular en su momento. ¿Acaso la causa ecológica en Galicia dejó de ser de interés social? ¿Por qué el servidor que aloja los recursos online de "Nunca Máis" ya no funciona? Será una desidia interesada que ya cumplió con su cometido crítico; es decir, parece que surge en un momento determinado y tuvo por fin último desgastar al partido gobernante en un momento de grave crisis política. Además, ¿Por qué tiene noticias más actuales la Web de "Nunca Máis” de Barcelona que la de Galicia? En definitiva aparecen dudas y sombras al respecto y es difícil posicionarse totalmente con una u otra teoría. Se apuntan interesantes interrogantes acerca del proceso pero también sugerentes investigaciones; Bonchek (1995) sostiene que existe brecha digital en las acciones colectivas y que finalmente acaban beneficiando a determinados grupos sociodemográficos; este sería un tema a investigar en el caso de "Nunca Máis”.

\section{5.- ANÁLISIS DE UN PARTIDO POLÍTICO: BNG. BLOQUE NACIONALISTA GALEGO. WWW.BNG-GALIZA.ORG}

El BNG es un frente político de Galicia, formado por militantes individuales. En su seno coexisten varios grupos y partidos organizados y reconocidos como tales por el propio BNG y en los cuales pueden participar los militantes del BNG; sin embargo, la mayor parte de la militancia, un $70 \%$, solo pertenece al BNG y a ninguna otra de las formaciones internas; a estos militantes se les llama independientes y su ideología se puede describir como nacionalista gallego de izquierdas. Por otro lado, el independentismo también tiene cierto calado entre su militancia especialmente en el sector más juvenil.

Actualmente están reconocidos como grupos dentro del BNG los siguientes: Unión do Pobo Galego (UPG), Esquerda Nacionalista (EN), el Partido Nacionalista GalegoPartido Galerista (PNG-PG), Unidade Galega (UG), Colectivo Socialista, Inzar y militantes independientes. Su portavoz y exvicepresidente de la Xunta de Galicia es Anxo Quintana. Fue fundado en 1982, ideológicamente es europeísta, de izquierdas, socialista, comunista y nacionalista gallego.

Su presencia institucional en 2008 estaba compuesta por 595 concejales, 15 diputados provinciales, 13 diputados autonómicos, 2 diputados en el Congreso de los Diputados y

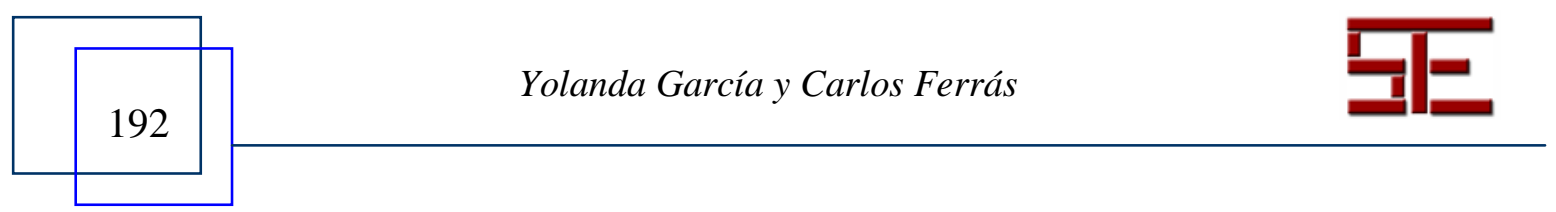




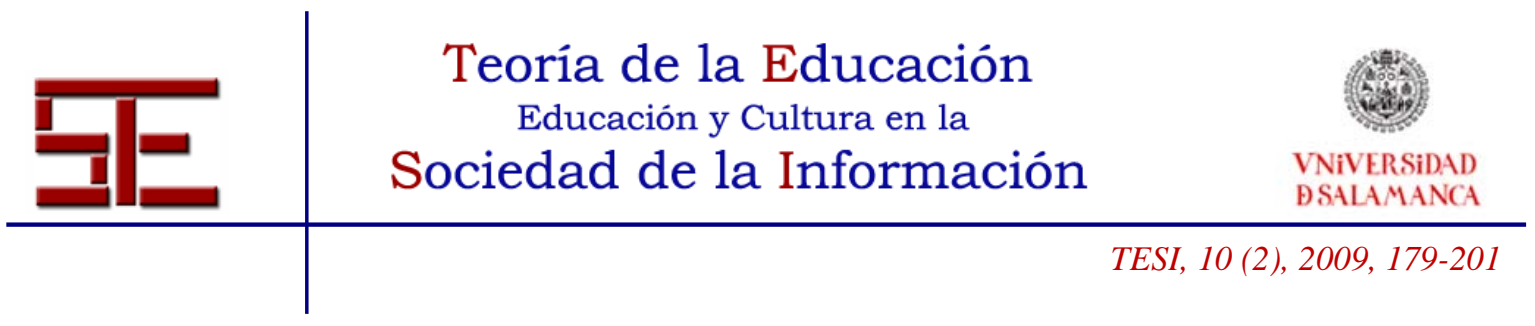

1 senador designado por el Parlamento de Galicia. Su carácter ha sido cada vez más de institución política comprometida con el gobierno de Galicia al tener un pacto y repartir 2009). En las elecciones generales de marzo de 2008 mantuvo su porcentaje de votos con 209.000 votos (12,07\% del censo de votantes de Galicia). Son muchos más votantes en los comicios autonómicos; en los últimos de 2005 el BNG tuvo 405.000 (18,7\% de los votantes totales). Aunque es difícil conocer el dato referido al número de militantes (no consta en la Red), las estimaciones recabadas en un sondeo personal entre militantes de dicho partido lo sitúan en torno a los 6.000-8.000 afiliados.

Respecto al análisis el contenido de la Web del partido, observamos que ha sido pensada, estructurada y diseñada para la difusión de información. Tiene una clara orientación periodística con teletipos, noticias, agenda de actividad de sus representantes en los parlamentos gallego y del Estado, con un servicio multimedia llamado TeleBNG que enlaza con un canal de YouTube donde se pueden ver videos institucionales y de propaganda política elaborados por subscriptores-colaboradores de la organización. Su objetivo es sobre todo facilitar y orientar la comunicación del Partido con los Medios; destaca un servicio de Teletipos al servicio de periodistas en busca de noticias.

Los recursos que genera son básicamente unidireccionales, es decir ofrece información a modo de publicidad, propaganda y marketing informacional. No existen instrumentos claros de intercomunicación social, pues no permiten foros abiertos, Chats, ni encuestas de opinión para sondear en la Red las posiciones de la militancia respecto a sus acciones políticas en las instituciones. Es muy interesante el servicio de Blogs con cargos políticos diversos en los municipios pero no son efectivos al no potenciar la interactividad con los ciudadanos.

La participación política del ciudadano tan solo es posible a través de un diario a modo de Blog con su líder nacional “Anxo Quintana” que periódicamente, con frecuencia semanal, escribe sobre temas diversos de su actividad diaria en la Xunta de Galicia o respecto de las iniciativas del BNG en los diferente foros políticos donde participa; es curioso que en los textos el líder del BNG se refiere a correos electrónicos que le envían diferentes personas pero, sorprendentemente, dichos mensajes están ocultos; al final parece un monólogo sin sentido que no contribuye a la participación social. Todo apunta a que es una Web orientada a la diseminación de información hacia los medios de comunicación y hacia la militancia y simpatizantes comprometidos con el BNG.

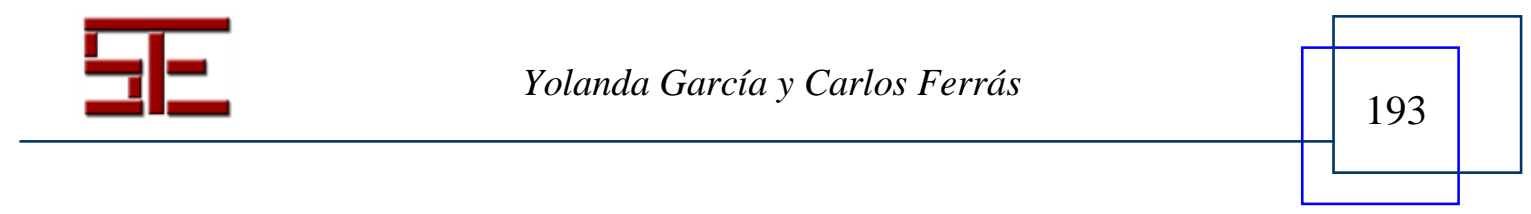




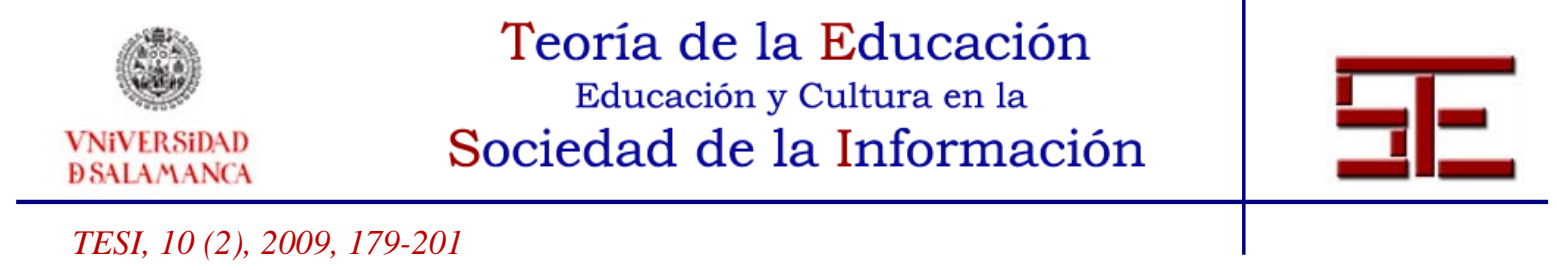

¿Cuáles pueden haber sido las motivaciones y los objetivos del partido para la construcción de la página Web? Teniendo en cuenta las características de la Web interpretamos que los motivos han sido diversos. Pero principalmente el de difundir información estratégica hacia los medios de comunicación y periodistas en general. Parece que han tratado de evitar intermediarios buscando hacer más fluida la información oficial del partido acerca de sus actividades institucionales. También creo que la cuestión de imagen de marca vinculada a las nuevas tecnologías ha sido importante; se trata de estar "al día” en el uso de las TIC como correspondería a un partido moderno y avanzado. La horizontalidad en los flujos de información y comunicación con las asambleas locales, municipales, del BNG pudo ser un objetivo no alcanzado. La reducción de los costes respecto a la difusión de información también pudo haber sido un objetivo.

¿Cuáles pueden ser los efectos de la Web sobre el público potencial del partido? La página Web del BNG no invita a la participación "feed back" entre políticos y ciudadanos. Observamos que es una Web informativa; con teletipos y noticias a modo de periódico digital. Claramente es una Web con una estrategia de difusión y comunicación de información. Sigue una línea de “Top Down” al no existir canales de participación claramente visibles. No es una Web que busque la opinión de los ciudadanos y no fomenta la opinión crítica. El "Bottom Up” parece que se intenta con la estructura de Webs municipales y comarcales del BNG pero al observarlas con detenimiento se constata que son de nuevo instrumentos de difusión de información local referida a la actividad institucional en las alcaldías, concejalías, etc. Los efectos de la Web del BNG sobre su público potencial serán siempre limitados; la Web contribuye a difundir y producir información institucional que solo puede atraer la atención de militantes, simpatizantes, cargos políticos y analistas políticos de los medio de comunicación. Difícilmente dicha Web atrae la atención o la participación de ciudadanos en general. Es una Web que refuerza la comunicación unidireccional del partido con sus bases y complementa su actividad "off-line". Es una Web tipo "show window” (Gibson, 2003) que no consigue atraer la mirada y participación de los ciudadanos.

La presencia en Internet del partido y las características de esta presencia está condicionada por variables de tipo institucional, como por ejemplo el sistema electoral o el grado de descentralización territorial del país. Está condicionada por el propio desarrollo de la Sociedad de Información en Galicia y en España. No debemos olvidar que el BNG es un partido Nacionalista, territorialmente ceñido a la Comunidad

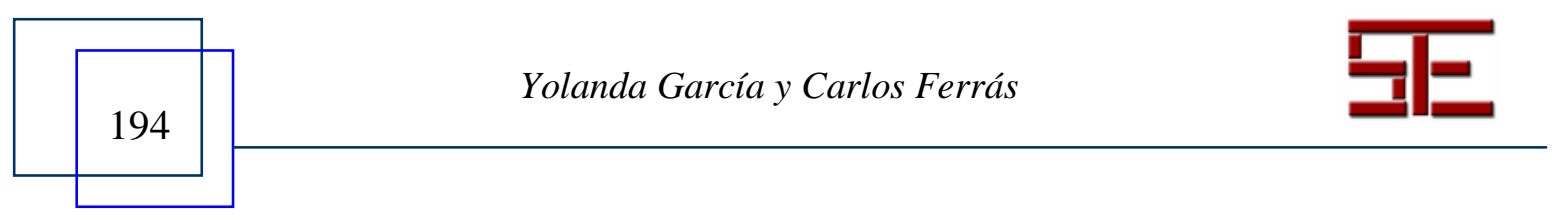




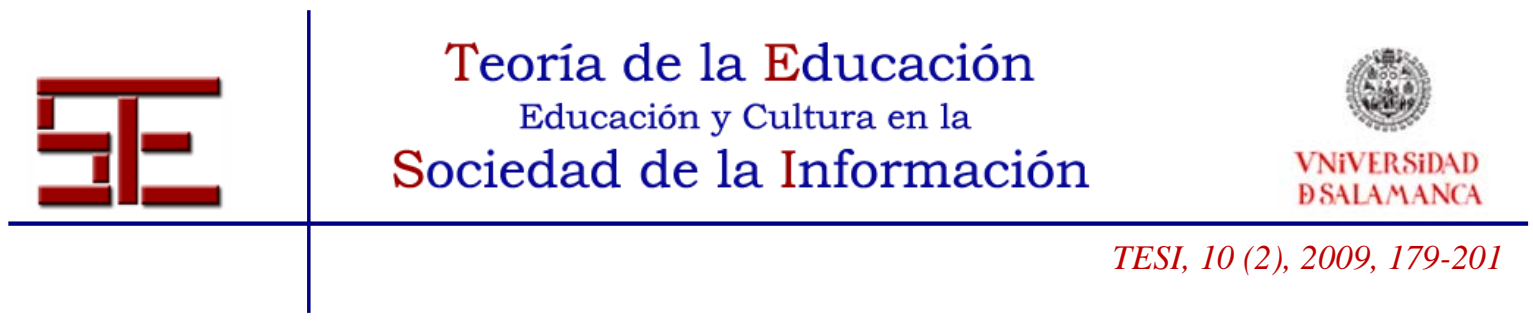

Autónoma gallega y a la estructura del Estado de las Autonomías. Sus estrategias de comunicación están muy vinculadas a los medios tradicionales pues el uso de Internet no alcanza al 40\% de la población gallega (IGE, 2006); los potenciales votantes que pueden ser atraídos a través de Internet y las Web son un nicho de mercado muy reducido. Este hecho refuerza la estrategia de divulgación de su Web orientada a los Mas Media tradicionales en una sociedad que no usa mayoritariamente las TIC. La Web del BNG es un factor importante en su estrategia política; con ella consigue difundir y producir información sobre sus actividades institucionales; ofrece recursos multimedia como un canal de video en YouTube y galerías de imágenes vinculadas a las noticias destacadas. Sin embargo, dicha Web se utiliza para reforzar la estrategia de comunicación “off-line” y se supedita a ella; no tiene un valor añadido de intercomunicación o atracción de los ciudadanos; es más bien una plataforma de comunicación y publicidad. La información que difunde dicha Web está orientada claramente hacia el ensalzamiento de los líderes y el trabajo e iniciativas institucionales de sus Alcaldes, Concejales, Conselleiros..., en los parlamentos regional y estatal, gobiernos (locales y autonómicos), etc.

¿Hasta qué punto la brecha digital es un elemento que reduce la importancia del impacto de la Web del partido? El impacto de la Web del BNG se reduce en gran medida al estar condicionada por el escaso uso de la comunicación mediada por ordenador en una Sociedad-Objetivo como la gallega. Es una Web que no cuenta con foros dinámicos, chats o encuestas, en la que dominan las características unidireccionales en los flujos de información que genera. Teniendo presente que la estrategia de "show windows" es común en las Webs de los partidos propios de democracias maduras en sociedades avanzadas (Gibson, 2003 y Sadow y James, 2000), podemos intuir que la situación de atraso informacional del caso gallego y del BNG en particular se enmarca en un contexto generalizable a nivel de España y de otros partidos políticos. El BNG está lejos de ser un "ciberpartido" y su concepción es tradicional-institucional (siguiendo la definición de Margetts, 2001).

\section{6.- ANÁLISIS DE LA WEB DEL PARLAMENTO DE GALICIA. WWW.PARLAMENTODEGALICIA.ORG}

En el parlamento gallego están representados los partidos políticos de ámbito autonómico y estatal. Es una institución joven en la medida de que el Estatuto de Autonomía de Galicia fue aprobado en 1981 y su creación emana de dicha Norma. Es también un caso interesante porque debería reflejar en su Web el actual desarrollo del

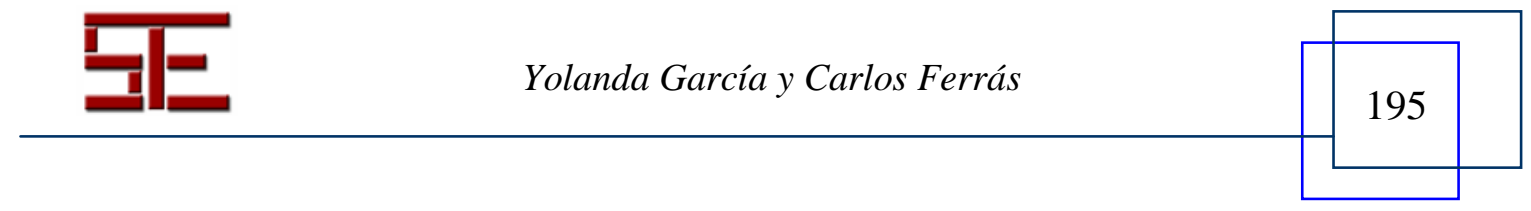




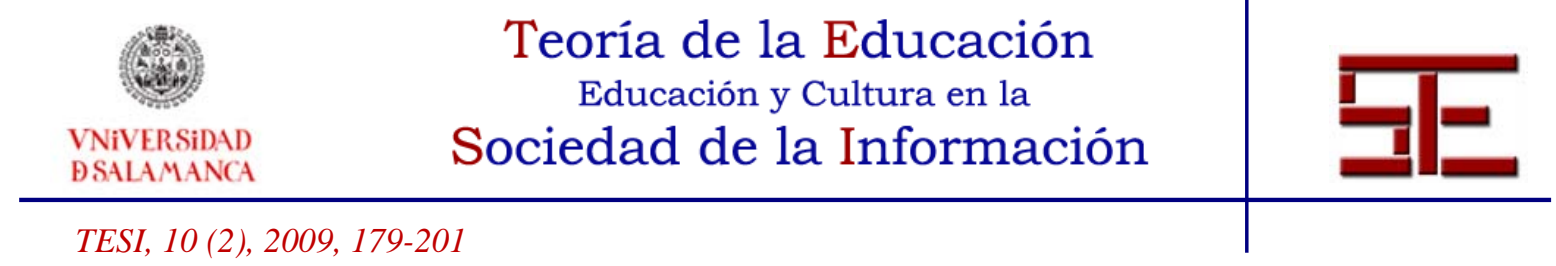

Estado de las Autonomías. Observamos que los Parlamentos Autonómicos de las nacionalidades históricas españolas son más próximos a los ciudadanos de su ámbito territorial que las cámaras alta y baja del Estado, Congreso de los Diputados y Senado.

La Web del Parlamento de Galicia se estructura en cuatro grandes bloques principales: Actividad del Parlamento, Información Institucional, Participación Ciudadana y Centro de Prensa. Todos ellos recogen abundante información de textos, a veces acompañados de material multimedia como fotografías y videos. Es información diversa y específica sobre las actividades diarias del Parlamento, de su Presidenta, de los Parlamentarios y de los Grupos Políticos. Ofrece en portada una Agenda completa con el calendario de sesiones de los Plenarios, Comisiones, etc., incluso con el orden del día, documentos institucionales que van a ser tratados en los debates, etc.

Es una Web que ofrece un interesante servicio de documentación sobre la actividad parlamentaria; que ofrece a modo de periódico electrónico con noticias de texto y fotografías, acompañadas de recursos multimedia, no siempre, y documentos pdf relacionados. Permite una visita virtual con una descripción de las dependencias, salas, etc. del Parlamento. Ofrece la posibilidad de contactar para solicitar visitas presenciales de los ciudadanos.

En cuanto a la comunicación entre los representantes y los representados la Web del Parlamento de Galicia ofrece apartados específicos con información sobre los Grupos Parlamentarios (BNG, PSOE y PP), con información organizada, de nuevo, como un periódico digital con noticias acerca de sus intervenciones, propuestas parlamentarias y actividades en general; permite el envío de correos electrónicos a los parlamentarios, pero tan solo a aquellos que ofrecen información personal con currículo, galería de imágenes y excepcionalmente Blog y página Web personal. Se pudo constatar que en noviembre de 2008 en el caso de BNG ninguno de sus diputados ofrecía dichos servicios de comunicación e información.

La sección denominada "Lexisla con Nós" (legisla con nosotros) permite enviar opiniones sobre debates abiertos, sobre proposiciones de normas y leyes en general, a cualquier ciudadano interesado; incluso pudimos observar que se abren debates muy interesantes. Es un foro moderado y una vez que envías tú mensaje pasan varios días antes de verlo publicado en la Web, incluso pudimos comprobar que nadie se dirige al emisor para comunicarle la aceptación o rechazo de su mensaje. La participación es desigual, en algún caso cuentan con 45 entradas, pero mayoritariamente apenas tienen

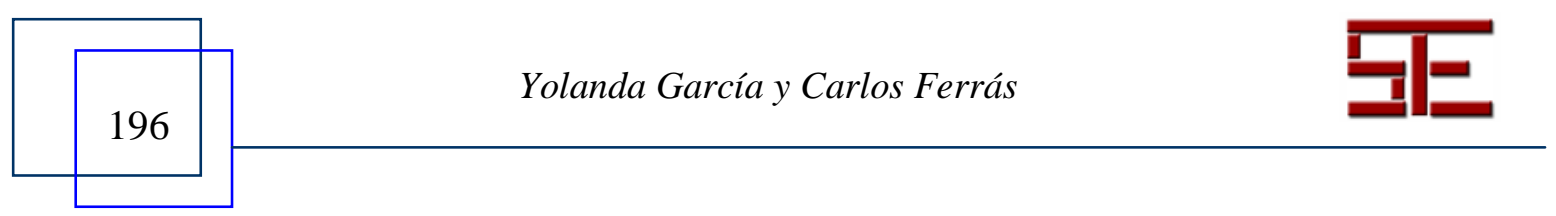




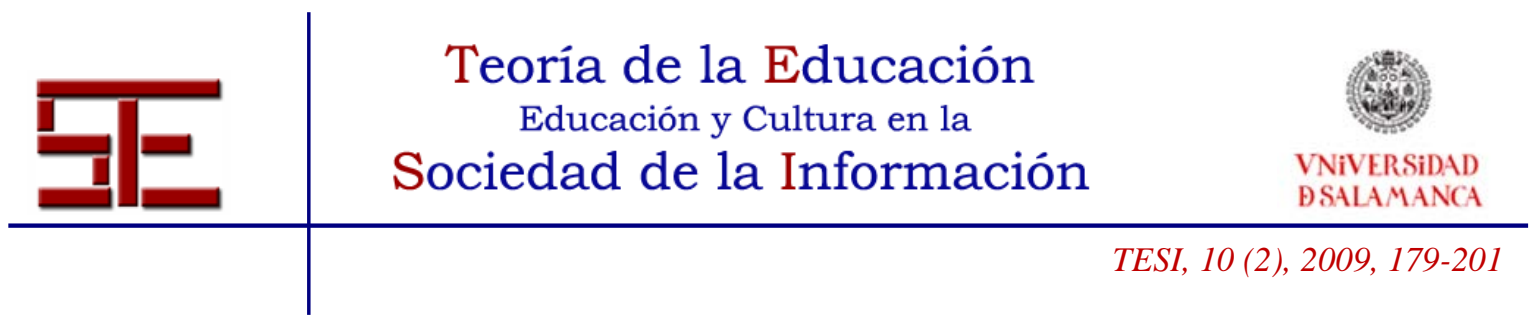

participación. Por el contenido de los mensajes se intuye que la participación "on-line” es protagonizada por los propios parlamentarios, cargos políticos o militantes activos de los diversos partidos políticos con representación en la cámara.

También es interesante el servicio de suscripción a noticias y producción de documentos parlamentarios por temas de interés. El ciudadano tiene la opción de subscribirse libremente a diversos temas y asuntos para recibir por mail puntual información.

Podemos preguntarnos por si ¿el marco institucional determina las características de esta Web? Consideramos que sí la determina en el sentido de refleja rasgos propios de un sistema de democracia representativa; en relación con el hecho de que los parlamentarios y grupos políticos del Parlamento de Galicia se muestran en la Red como representantes de los ciudadanos y actúan corporativamente interpretando sus posiciones políticas. No se muestran como delegados de los votantes y no propician decididamente el diálogo directo con los ciudadanos a través de las Tics.

Por otro lado, el desarrollo de la Sociedad de la Información y el uso de las Tics en Galicia se encuentran en estado de retraso respecto a Europa y al resto de España. Los datos de usuarios de Internet se sitúan en torno al 40\% de la población (datos Instituto Galego de Estadística, 2006).

Pero ¿La Web supone una mejora de la función representativa de la Cámara? Notamos que mejora considerablemente la actividad del Parlamento, pues contribuye a la difusión de información de sus actividades, a la imagen institucional, a la mejora, rapidez y eficiencia de su gestión interna y permite una mayor rapidez de los flujos e intercambios de información. En cuanto a la mejora de la representación de la Cámara todo indica que efectivamente puede mejorarla pues la Web aproxima la institución a los ciudadanos y la hace más transparente; sin embargo, observamos que se encuentra todavía en un estado inicial. La participación ciudadana es limitada y no existe una cultura de participación “on-line” en la ciudadanía ni entre los diputados. En dicha Web se percibe más una función de delegación que de representación de la ciudadanía.

\section{7.- SUMARIO CRÍTICO.}

La interacción directa los políticos y los ciudadanos, antes negada por la televisión, es ahora impulsada por la comunicación electrónica a través de Webs, Blogs o Wikis. El acceso a las Nuevas Tecnologías no es democrático pues es socialmente restringido; pero a sus usuarios si les permite una nueva lógica de participación y acción; pensemos

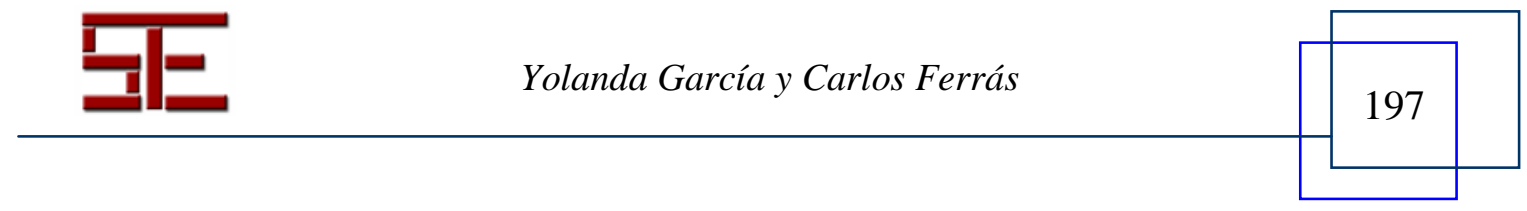




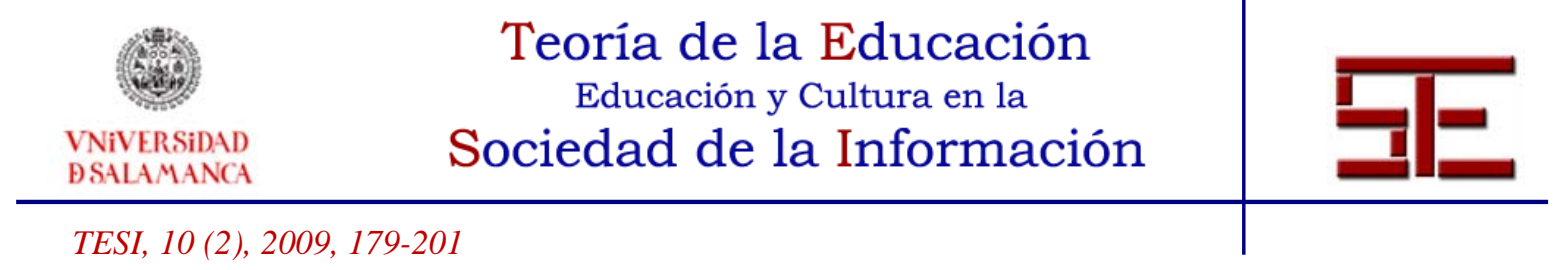

en la interacción que permiten los Smartmobs, SMS, Youtube, etc. Son muy positivas las contribuciones de las Tics a la formación de la opinión pública y al ejercicio de la libertad de expresión y movilización social (permiten canales verdaderamente democráticos y abiertos a todo el mundo). Coincidimos plenamente con Lara Otaola (2007) en considerar a "la democracia como el gobierno de la opinión” y, es por ello, que debemos ser conscientes de los enormes avances que las Nuevas Tecnologías aportan al respecto. Sin embargo, desde un punto de vista negativo también es sumamente importante considerar que la inmensa información de la Red puede llevar a una sociedad desinformada. Podemos preguntarnos si la "superficialidad de Internet" desembocará en una televisión de tercera generación; podrían los internautas llegar a ser usuarios con informaciones simples y vanas; sería una Internet para un público pasivo. La información en Internet debe ser libre e imparcial y autónoma, pero existe el peligro de que las Nuevas Tecnologías puedan utilizarse como nuevas herramientas políticas para una propaganda manipuladora y desinformada. El binomio Oferta-Demanda permeabiliza los contenidos de las Webs, Blogs y otras redes haciendo que la información pueda llegar a ser superficial a partir de la mercadotecnia política. La incapacidad del Estado de dar herramientas de comprensión a sus ciudadanos, la falta de orden en la información "googlelizada" en la red, las preferencias personales de la sociedad y la lógica del dinero, del mercado y economía de consumo que invaden la razón son riesgos que pueden convertir estas herramientas democráticas en medios de desinformación, pues sub-informan y venden en lugar de informar y generar opinión. En suma, como dice Lara Otaola (2007), hoy en día los ciudadanos en cuanto a nuestros comportamientos políticos, y en función del uso o no uso que hagamos de la Red y de las Tics, tenemos la opción de "elegir entre la ceguera, adorar a una alfombra o comer helado”. O lo que es lo mismo ignorarlo todo, creerlo todo, o conformarnos con algo.

Observamos que las Webs de instituciones como la del Parlamento de Galicia, la de la Xunta de Galicia, la de la plataforma ciudadana “Nunca Máis” y la del partido político Bloque Nacionalista Galego se encuentra más en una fase de "performance” (Gibson, Lusoli y Ward, 2004) que de "reinforcement” (Bellamy y Raab, 1999), al no desarrollar plenamente las potencialidades de comunicación y al hacer más un uso interno que externo de las Nuevas Tecnologías.

Desde una perspectiva general, en cuanto al desarrollo futuro de las Webs de contenido político, pensamos que estas evolucionarán positivamente hacia formas de comunicación más interactivas. Es decir, desarrollarán formas de democracia electrónica donde los representantes políticos interactuarán con los ciudadanos más

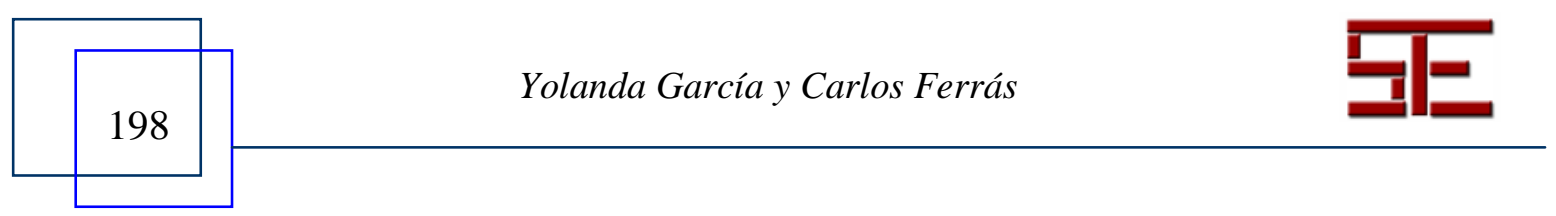




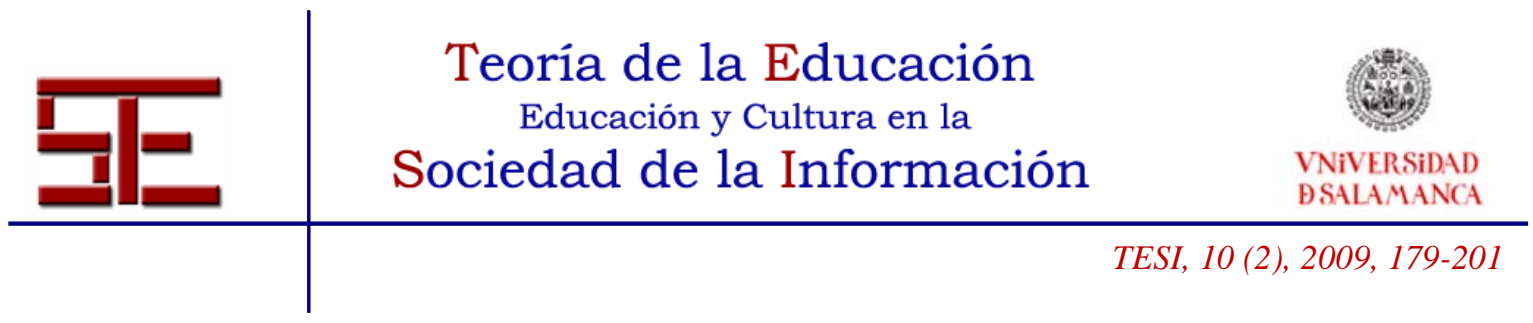

como representantes que como delegados. Las Webs parlamentarias y de los partidos políticos facilitarán los contactos y comunicación en general con la ciudadanía y no tan solo con los militantes, diputados, o personas más comprometidas con el partido político afín. Tendrán foros de discusión, e-mail generalizado y encuestas electrónicas para llevar a cabo sondeos de opinión. Todo ello acompañado de información amplia y transparente sobre funciones, historia, sistema electoral, procedimientos legislativos, agenda, leyes en trámite y aprobadas, etc. Como dice Lara Otaola (2007) "para que una multitud funcione políticamente es preciso que el juego democrático en el que está inmersa sea inteligente” y todo apunta a que las nuevas tecnologías de la comunicación lo facilitan.

\section{REFERENCIAS BIBLIOGRÁFICAS}

BATLlE, A., CERRILlO, A. (2004): Tics y procesos políticos, Documentos UOC XP04/63038/01142.

BARRERO, F., CRIADO, J.I., RAMILO, M.C. (2006): Política y Web 2.0, III Congreso Online del Observatorio para la Cibersociedad.

BENNET, L. (2003): New Media Power: The Internet and Global Activism. En N. Couldry y J. Curran, Contesting Media Power, Ed. Rowman and Littlefield.

BONCHEK, M.S. (1995): Grassroots in Cyberspace: Using Computer Networks to Facilitate Political Participation, Documento presentado en el congreso annual de la Midwest Political Science Association. Chicago, abril.

CRIADO, J.I.; RAMILI, Ma C. (2001): E-Administración: ¿Un reto o una nueva moda? Problemas y perspectivas de futuro en torno a Internet y las tecnologías de la información y la comunicación públicas del siglo XXI. En IVAP.

CONSELLERÍA DE INDUSTRIA (2007): Plan Estratégico Galego para a Sociedade da Información (PEGSI). Xunta de Galicia, Santiago de Compostela.

DUNLEAVY, P. et al. (2003): E-goberment and policy innovation in seven liberal democracies, Paper for the Political Studies Association's Annual Conference, Leicester University.

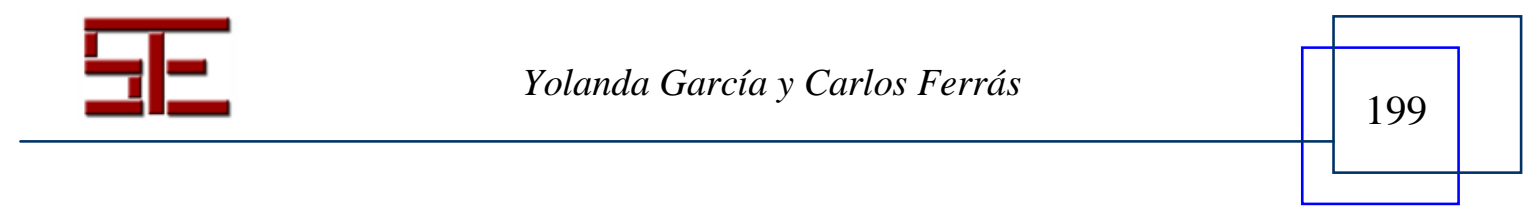




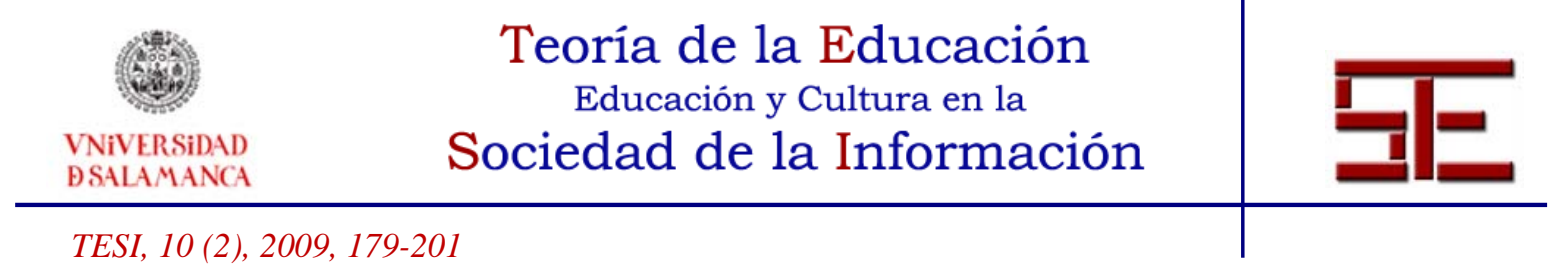

FERRÁS, C., ARMAS, F., MACÍA, X.C., GARCÍA, Y. (2006): Sociedad de la Información en espacios periféricos. Nuevas formas de exclusión social. Universidad de Santiago de Compostela.

GIBSON, R.K. (2003): Web Campainig from a Global Perspectiva. Documento presentado en el congreso The IT Revolution and the Transformation of Society. Tokio.

INSTITUTO GALEGO DE ESTADÍSTICA (2008). www.ige.eu. Datos encuestas hogares.

INSTITUTO NACIONAL DE ESTADÍSTICA (2008). www.ine.es. Datos encuesta hogares.

KUNSTELJ, M.; VINTAR, M. (2004): Evaluating the progress of e-goberment development: critical analysis of currents approaches, Documento presentado en el Congreso Annual del Grupo de Administración Pública Europa.

LARA OTAOLA, M. (2007): Nuevas Tecnologías de Comunicación: ¿Oportunidad o riesgo para la Esfera Pública y la Democracia?, en Razón y Palabra 54.

LUSOLI, W., WARD, S. (2003): Hunting Protestors Mobilisation, Participation, and Protest Online in the Countryside Alliance. Documento presentado en el congreso annual del European Consortium for Political Research.

MARGETTS, H. (2001). The “ciberparty”. Documento presentado en el congreso anual del European Consortium for Political Research. Genoble.

NORRIS, P. (1999): Who Surfs Café Europa? Virtual Democracy in the US and WesternEurope, Harvard University, J.F.K. School of Goberment.

NORRIS, P. (2004): Building Knowledge Societies: The Renewal of Democratic Practices in Knowledge Societies, Informe para la UNESCO.

SADOW, J.D.; JAMES, K. (2000): Atheory of Internet Political Campaigning: A Revolution that Isn't, Yet. Documento presentado en el Congreso Anual de la Southwestern Political Science Association. Galveston.

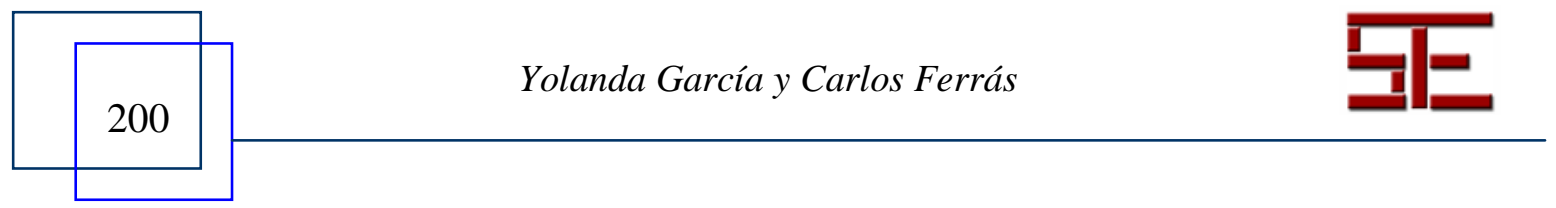




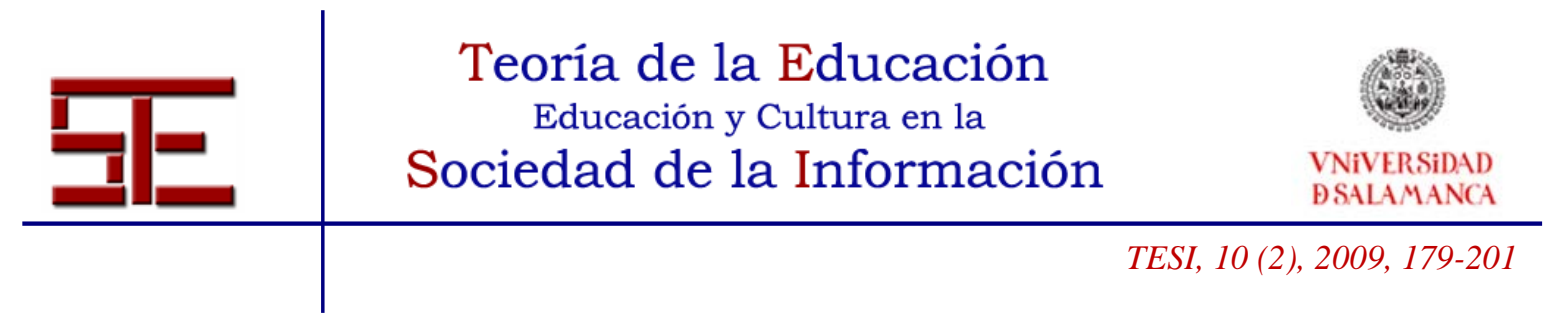

TORRES, P. (2005): Cambios en las formas de comunicación, ¿Cambios en las formas de hacer política?, en Gobernanza. Revista Internacional para el desarrollo humano 36.

Para citar la presente editorial puede utilizar la siguiente referencia:

Ferrás Sexto, C. \& García, Y. (2009). ¿Son las tecnologías de la información capaces de cambiar las formas de hacer política? Estudio de casos en Galicia, en Ortega Sánchez, I. Ferrás Sexto, C. (Coord.) Alfabetización Tecnológica y desarrollo regional [monográfico en línea]. Revista Electrónica Teoría de la Educación: Educación y Cultura en la Sociedad de la Información. Vol. 10, $\mathrm{n}^{\circ}$ 2. Universidad de Salamanca [Fecha de consulta: $\mathrm{dd} / \mathrm{mm} / \mathrm{aaa}]$.

http://campus.usal.es/ revistas_trabajo/index.php/revistatesi/article/view/7513/7544

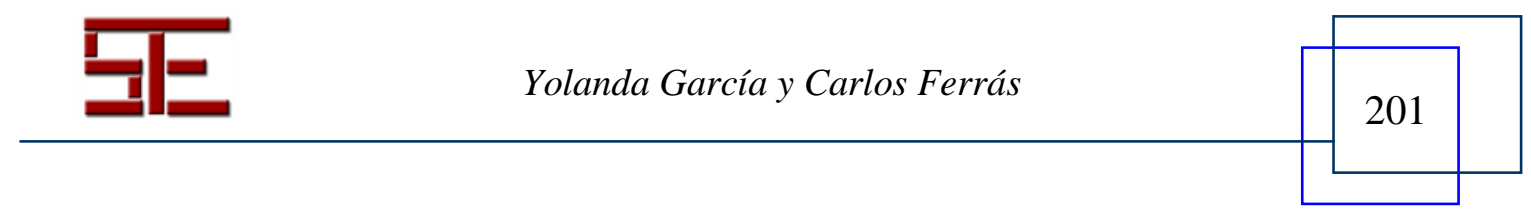

